\title{
Transcriptomic comparison between two Vitis vinifera L. varieties (Trincadeira and Touriga Nacional) in abiotic stress conditions
}

Margarida Rocheta ${ }^{1 \dagger}$, João L. Coito ${ }^{1 \dagger}$, Miguel J. N. Ramos, Luísa Carvalho ${ }^{1}$, Jörg D. Becker², Pablo Carbonell-Bejerano ${ }^{3}$ and Sara Amâncio ${ }^{1 *}$

\begin{abstract}
Background: Predicted climate changes announce an increase of extreme environmental conditions including drought and excessive heat and light in classical viticultural regions. Thus, understanding how grapevine responds to these conditions and how different genotypes can adapt, is crucial for informed decisions on accurate viticultural actions. Global transcriptome analyses are useful for this purpose as the response to these abiotic stresses involves the interplay of complex and diverse cascades of physiological, cellular and molecular events. The main goal of the present work was to evaluate the response to diverse imposed abiotic stresses at the transcriptome level and to compare the response of two grapevine varieties with contrasting physiological trends, Trincadeira (TR) and Touriga Nacional (TN).

Results: Leaf transcriptomic response upon heat, high light and drought treatments in growth room controlled conditions, as well as full irrigation and non-irrigation treatments in the field, was compared in TR and TN using GrapeGene GeneChips ${ }^{\oplus}$. Breakdown of metabolism in response to all treatments was evidenced by the functional annotation of down-regulated genes. However, circa $30 \%$ of the detected stress-responsive genes are still annotated as «Unknown» function. Selected differentially expressed genes from the GrapeGene GeneChip ${ }^{\circledR}$ were analysed by RT-qPCR in leaves of growth room plants under the combination of individual stresses and of field plants, in both varieties. The transcriptomic results correlated better with those obtained after each individual stress than with the results of plants from field conditions.

Conclusions: From the transcriptomic comparison between the two Portuguese grapevine varieties Trincadeira and Touriga Nacional under abiotic stress main conclusions can be drawn: 1. A different level of tolerance to stress is evidenced by a lower transcriptome reprogramming in TN than in TR. Interestingly, this lack of response in TN associates with its higher adaptation to extreme conditions including environmental conditions in a changing climate; 2. A complex interplay between stress transcriptional cascades is evidenced by antagonistic and, in lower frequency, synergistic effects on gene expression when several stresses are imposed together; 3 . The grapevine responses to stress under controlled conditions are not fully extrapolated to the complex vineyard scenario and should be cautiously considered for agronomic management decision purposes.
\end{abstract}

Keywords: Grapevine, Field Conditions, Controlled Conditions, Microarray, Gene expression, Varietal diversity

\footnotetext{
*Correspondence: samport@isa.ulisboa.pt

${ }^{\dagger}$ Equal contributors

${ }^{1}$ Instituto Superior de Agronomia, LEAF, Linking Landscape, Environment,

Agriculture and Food, Universidade de Lisboa, 1349-017 Lisboa, Portugal

Full list of author information is available at the end of the article
}

(c) 2016 The Author(s). Open Access This article is distributed under the terms of the Creative Commons Attribution 4.0 International License (http://creativecommons.org/licenses/by/4.0/), which permits unrestricted use, distribution, and reproduction in any medium, provided you give appropriate credit to the original author(s) and the source, provide a link to the Creative Commons license, and indicate if changes were made. The Creative Commons Public Domain Dedication waiver (http://creativecommons.org/publicdomain/zero/1.0/) applies to the data made available in this article, unless otherwise stated. 


\section{Background}

Grapevine (Vitis vinifera L.) is among the most economically important crops worldwide. According to the International Organization of Vine and Wine, in 2013, grapevine occupied more than 7,500 thousand hectares in cultivated areas. Nevertheless, in 2012, wine production decreased by $6 \%$ in Europe, mainly due to weather conditions (http://www.oiv.int/en/). Although Mediterranean regions offer among the best climate conditions for viticulture [1, 2], the soil and atmospheric water deficits along with high summer temperatures can have a negative impact on crop yield and fruit quality [3]. Furthermore, it is expected that impending climate changes may significantly impair grapevine production and quality $[1,4,5]$.

The major and most relevant abiotic stresses that can affect grapevine production in the Mediterranean region are drought, excessive light and excessive heat [6]. In field conditions it is rare that plants are affected by only one abiotic stress. Plants subjected to drought are usually also affected by heat and, sometimes, by excessive light which can cause photoinhibition [7]. Plants, as sessile organisms, are able to set in motion several mechanisms to deal with and to overcome environmental constraints. Response to abiotic stress is highly complex and involves the interplay of different responses at plant and cell levels. A cascade of molecular, cellular and physiological events can occur simultaneously and very rapidly. However, experimental approaches show that the processes triggered by each individual abiotic stress differ significantly and show little overlap [7, 8]. In recent years, many advances have been made towards understanding how plants respond to abiotic stresses, individually or in combination $[9,10]$. Although large amounts of data on the expression of genes related to abiotic stress are available, the challenge now is to connect those genetic profiles to changes in plant physiology. Concerning grapevines, the varieties Touriga Nacional (TN) and Trincadeira (TR) are known to be among the most important native varieties in Portugal, used to produce high quality red wines. Trincadeira is widely cultivated in the south of Portugal as it grows well in hot, dry and bright areas while TN, formerly cultivated in the north of Portugal [11] is nowadays cultivated throughout the whole Portuguese territory. The choice of these varieties was brought about due to contrasting physiological responses to stress. Touriga Nacional has a higher capacity to dissipate heat through evaporative cooling and is better adapted to warm climate conditions, as long as no water stress occurs [12]. Upon heat stress, TR is more intensely affected and for a longer period than $\mathrm{TN}$, up-regulating several antioxidative stress genes [13]. In addition, a high throughput search for transcriptomic responses increases the chance of finding key regulatory genes and proteins [7]. Usually the first processes to be affected by abiotic stress are photosynthesis and cell growth with subsequent issues in plant development. These effects can be either direct, by a decrease in available $\mathrm{CO}_{2}$ due to stomata closure, or indirect, by the onset of oxidative stress, a secondary effect of most abiotic stresses, which can be deleterious to the photosynthetic machinery and to other cellular mechanisms [7]. All these responses are also described as contributing to acclimation, and then to the alleviation of abiotic stress damage $[9,10,14,15]$. Recent advances in understanding the response to abiotic stress have unravelled several cell signalling pathways interconnected at many levels. They were clearly revealed by approaches using the combination of abiotic stresses $[9,14]$ which affect the expression of hundreds of genes [8, 16, 17]. Considering transcriptomic microarray projects in grapevines under abiotic stresses it is possible to quote reports of studies conducted with leaves focusing on heat, cold, drought or excessive light [8, 18-20]. Meanwhile a comparative analysis of grapevine gene prediction introduced substantial progress in Vitis genome annotation and provided a significant incentive for novel transcriptomic studies [21]. In the present study, a transcriptomic analysis was performed on leaves of TR and TN in order to compare their response at gene expression level 1) upon the application of individual abiotic stress treatments (drought, W; heat, $\mathrm{H}$; high light, L) in growth room controlled conditions and 2) upon full irrigation (FI) versus no irrigation (NI) in hot and dry summer field conditions to test for the first time with these varieties, how irrigation can change transcriptomic response. To complement the microarray analysis of the three abiotic stresses, the expression of the most highly up- or down-regulated genes pinpointed through the array was quantified by RT-qPCR in leaves of growth room plants subjected to the combination of the abiotic stresses in pairs or in triplets. The rationale of this experiment was that individual stresses interact with each other after combined application, so the transcription of the set of genes that respond to controlled individual, combined or field imposed abiotic stress, was compared in TR and TN grapevine varieties.

\section{Results and discussion}

Trincadeira and Touriga Nacional show distinct physiological responses to abiotic stress

In our study, the first approach was to ascertain whether the stress treatments had in fact induced a physiological response. Chlorophyll fluorescence parameters reflect the maximum efficiency of PSII photochemistry in dark- and in light-adapted leaves (respectively, Fv/Fm and F'v/F'm). In growth room experiments, these parameters were affected by stress, 
suffering significant decreases in both varieties Trincadeira (TR) and Touriga Nacional (TN), although in a unique pattern in each variety (Table 1 ). Touriga Nacional was more significantly affected by individual stresses than TR while in this variety only double or triple stresses caused significant decreases. Similar in both varieties was the effect of heat stress $(\mathrm{H})$ as individual or combined treatment that indicate a direct influence on the photosynthetic apparatus (Table 1), similar to photosynthesis alteration in situations when drought was combined with other stresses, especially in $\operatorname{TR}[13,22]$. In field plants, pre-dawn leaf water potential and soil water content, confirmed the severe water stress affecting non irrigated plants in both varieties (Fig. 1a and b; Additional file 1). Previous results report that TN can withstand growth in warmer climates with higher levels of irradiance than TR, as long as water is available $[12,23]$. In these conditions TN maintains higher photosynthesis rates and chlorophyll fluorescence parameters than TR, which point to the absence of severe stress in $\mathrm{TN}$ [23].

Table 1 Chlorophyll fluorescence parameters measured in the two grapevine varieties, Touriga Nacional (TN) and Trincadeira (TR)

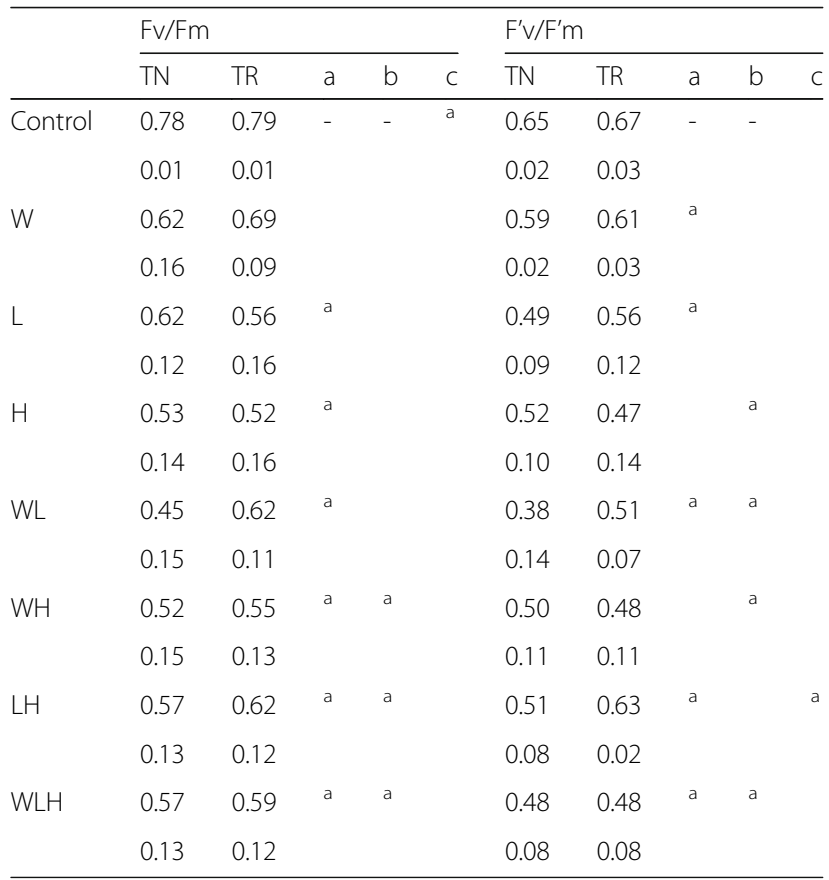

Plants were subjected to individual (water, $W$; light, $L$; heat, $H$ ) and combined stresses (WL; WH; LH; WLH) as indicated in Material and Methods. $F_{v} / F_{m}$ represents the maximum efficiency of PSII photochemistry in darkadapted leaves and $F_{v}^{\prime} / F_{m}^{\prime}$ corresponds to the maximum quantum efficiency of PSII in light-adapted leaves. Values are accompanied by the respective standard errors. Statistically significant differences after Tukey's multiple comparison tests for $p<0.05$ are the following: ${ }^{\mathbf{a}}$ in column a: significant difference between TN and the respective control; ${ }^{\mathbf{a}}$ in column b: significant difference between TR and the respective control; ${ }^{\mathbf{a}}$ in column c: significant difference between TN and TR within a stress treatment

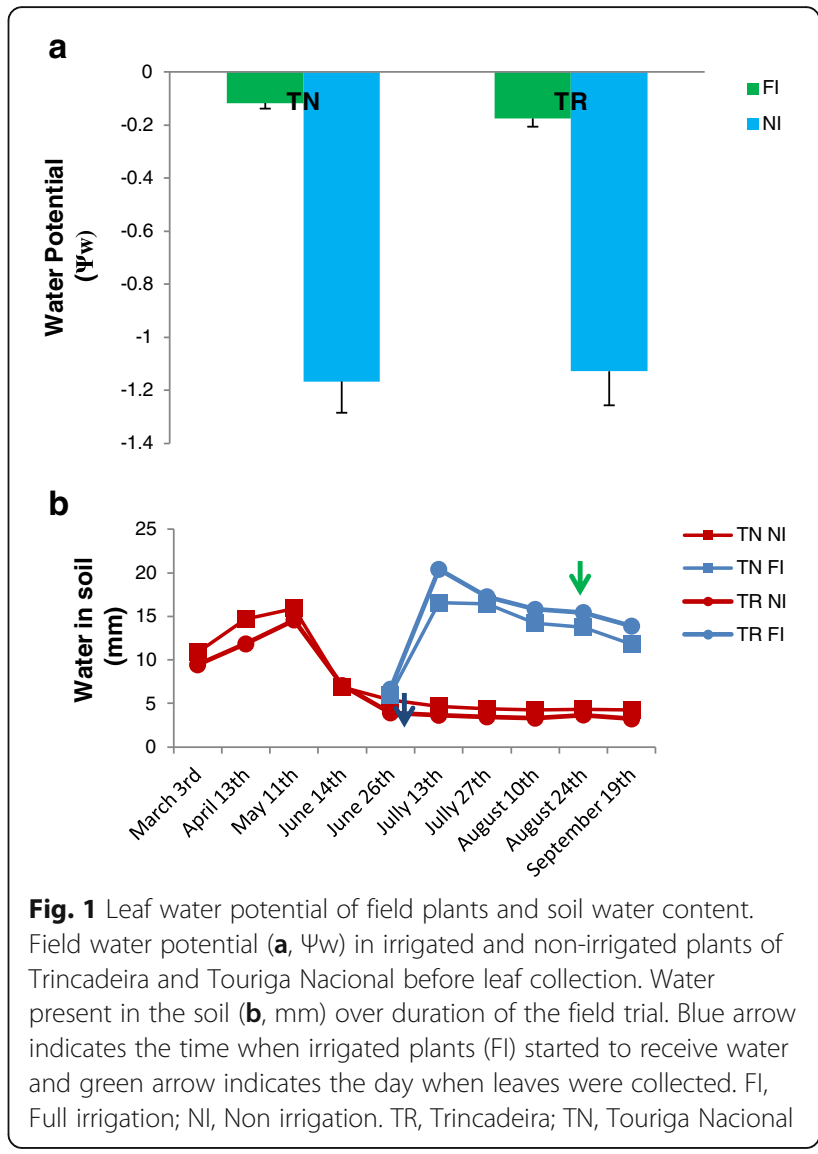

PCA and HCA analysis of microarray gene expression data show differential stress response tendencies

Transcriptome profiling was carried out in Trincadeira (TR) and Touriga Nacional (TN) leaf samples from the six different conditions tested: control, C; water deficit, $\mathrm{W}$; heat, $\mathrm{H}$; high light, $\mathrm{L}$ in the growth room, as well as upon full irrigation (FI) and no irrigation (NI) in the field vineyard. Three replicates per sample type as in Material and Methods were analyzed using GrapeGen Genechip microarrays, which represent more than $17 \mathrm{k}$ grapevine unigenes [24].

The microarray data was first analysed by means of principal component analysis (PCA) (Fig. 2) and hierarchical clustering analysis (HCA) (Additional file 2) in order to access the similarity of the sample replicates for each treatment and to identify the main sources of gene expression variation [25]. From the PCA of TR samples, the plot of principal component (PC) 1 (24.5\% of the variability) depicts a marked difference between water deficit (W) and the other conditions. Furthermore, a slight separation between control and L stress samples as well as two $\mathrm{H}$ stress replicates was observed, so it might be assumed that the strength of the stress response is explained by PC1 in Trincadeira individual stress (IS) samples. Also for Trincadeira IS samples, PC2 


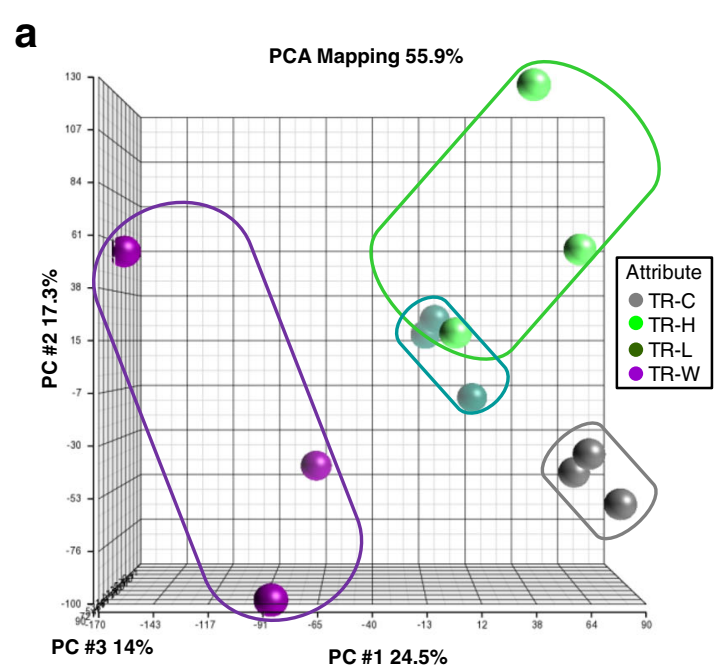

b

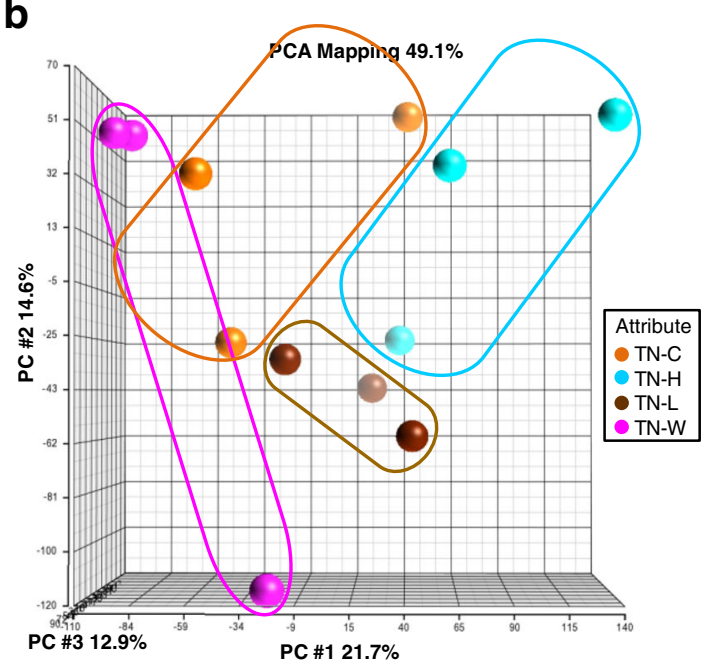

C

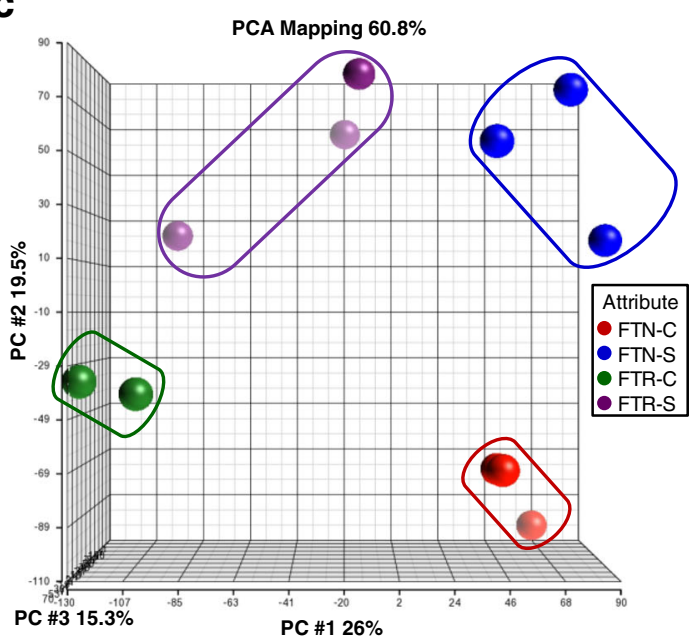

Fig. 2 Principal Component Analysis (PCA) of microarray results in growth room and field experiments. The PCA were performed with normalized expression of all the transcripts. a Trincadeira (TR) growth room; b Touriga Nacional (TN) growth room; c Field experiment with both varieties; $-\mathrm{C}$, growth room control; $-\mathrm{H}$, growth room heat stress; $-L$, growth room high light radiation stress; $-W$, growth room water deficit. FTN-C, Field full irrigation Touriga Nacional, control; FTN-S, Field non-irrigation Touriga Nacional, stress; FTR-C, Field full irrigation Trincadeira, control; FTR-S, Field non-irrigation Trincadeira, stress

(17.3\% of the variability) depicts variability within W and $\mathrm{H}$ replicates (Fig. 2a). Similarly, hierarchical cluster analysis (HCA) showed a separation between $\mathrm{W}$ and all other growth room TR samples. Moreover, HCA showed consistency between replicates in all conditions assayed for TR (Additional file 2). In Touriga Nacional IS samples a high variation was observed within replicates after all treatments except L (Fig. 2b), PC1 explaining $21.7 \%$ and PC2 $14.6 \%$ of the differences. The lack of homogeneity in TN samples can be assigned to a less clear effect of the treatments. This observation is further supported by the HCA (Additional file 2) where the replicates from different conditions did not cluster together. Regarding the PCA of field samples, PC1 (26\% of variation) separated the varieties and $\mathrm{PC} 2(19.5 \%)$ the irrigation regimes (Fig. 2c). Noticeably, lower response of TR to the field water deprivation treatment is evident in the separation of the samples in PC2. The three replicates of each variety cluster together upon the different experimental conditions, a pattern confirmed in the HCA (Additional file 2). In fact, the HCA showed consistency between replicates of both TN and TR field conditions that in turn were clearly separated from all growth room samples irrespective- of the genotype. The results confirm the different behaviour between $\mathrm{TN}$ and TR, which could be explained by the basal tolerance of TN $[12,13]$.

\section{Differential gene expression response between controlled} and field stress conditions

Transcripts significantly changing expression in response to water deficit (W), heat $(\mathrm{H})$ and high light (L) stress under controlled conditions, as well as field no irrigation (NI) treatment, were searched by comparison to the respective control samples (5\% False Discovery Rate - FDR). Remarkably, more down- than up-regulated genes were generally detected in response to individual stresses (ISs) in both varieties (Fig. 3a). However the number of responsive genes was significantly lower in $\mathrm{TN}$ in particular after W and $\mathrm{L}$ stress, respectively 136 and 318 in TN versus 3042 and 2618 in TR (Fig. 3b). High light and $\mathrm{H}$ are the stresses that showed the highest number of gene expression responses shared between the two varieties, 31 in total (most of them down-regulated) 


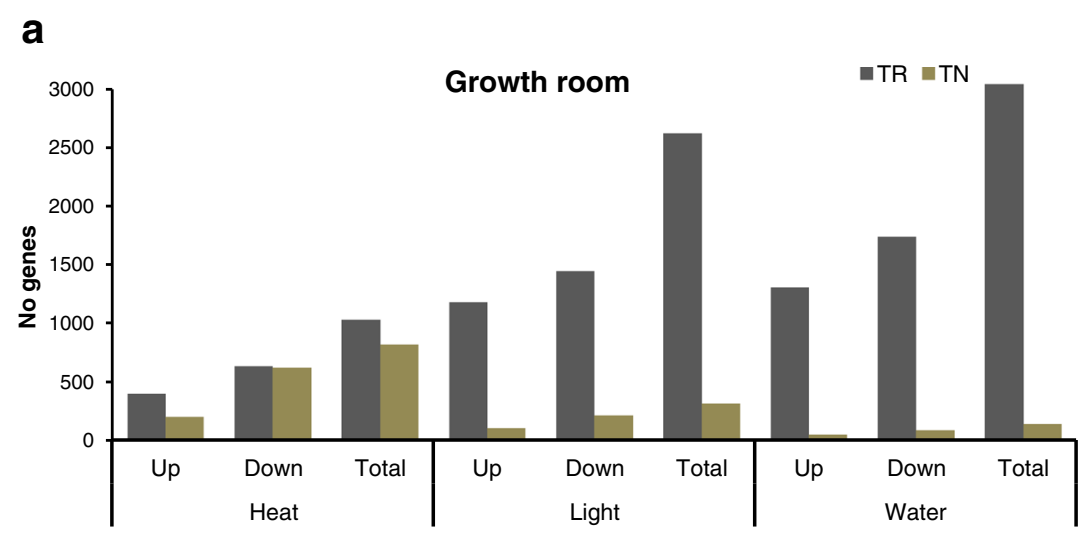

b

Trincadeira

Touriga Nacional
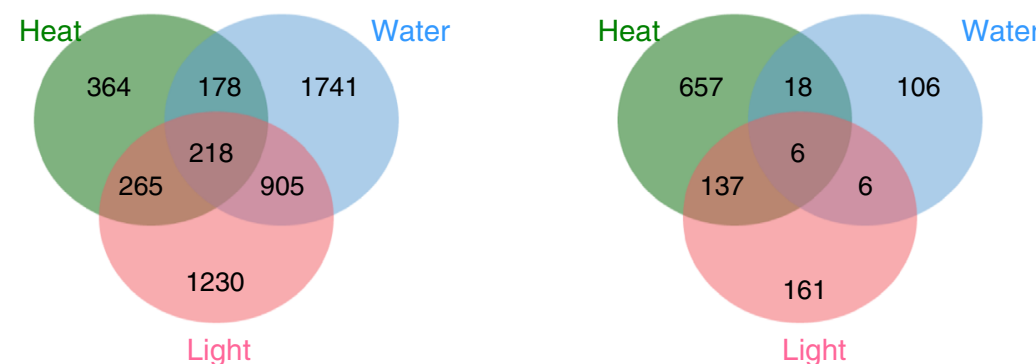

Light

C

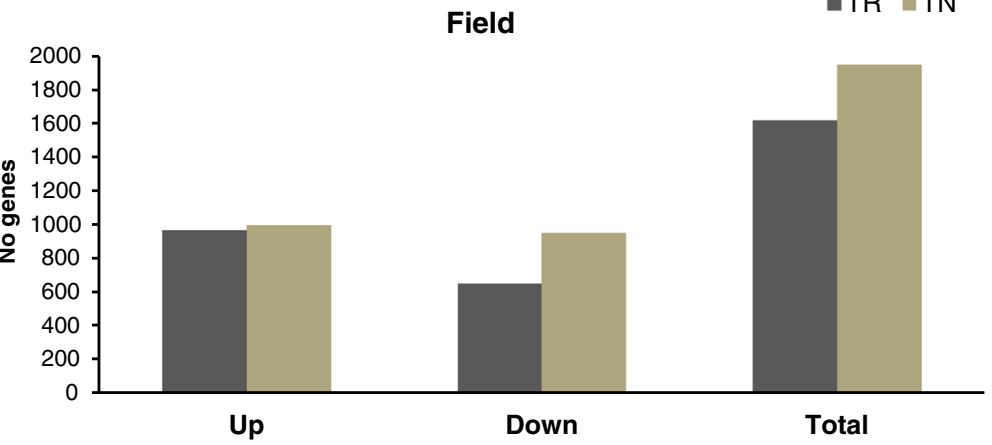

d
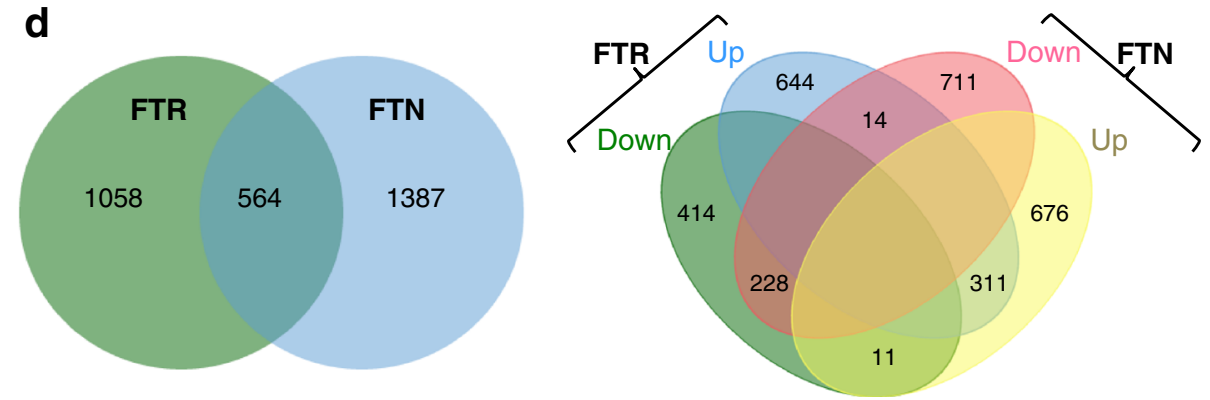

Fig. 3 (See legend on next page.) 
(See figure on previous page.)

Fig. 3 Differentially expressed genes in growth room and in field experiments. a Number of total, up- or down-regulated genes of the microarray showing significant expression changes after individual stresses in comparison to the control. b Venn diagrams showing the number of genes distinct or common to the different individual stresses. c Number of total, up- or down-regulated genes of the microarray showing significant expression changes in the field trial. $\mathbf{d}$ Venn diagrams showing the number of transcripts distinct or common to both varieties (left) and the up or down-regulated transcripts distinct or common to both varieties in the field stress trial in relation to control (right). Heat, High light, Water deficit in Trincadeira (left) and Touriga Nacional (right). Top, up-regulated genes; Bottom, down-regulated genes; TR, Trincadeira; TN, Touriga Nacional; FTN, Field Touriga Nacional; FTR, Field Trincadeira

(Additional file 3). These shared responsive genes code for an ELIP, a heat shock protein (HSP), an ethylene responsive factor (ERF), a nudix hydrolase and a calcium binding protein. It is interesting to highlight the transcripts coding for one zinc finger containing protein, one nudix hidrolase (NUDT17) and two ß-expansin annotated as VviEXPA18 and $V v i E X L B 4$ [26] Zinc finger proteins belong to a large eukaryotic TF family sharing $\mathrm{CnHn}$ motifs, which are involved in plant growth and development and also in responses to environmental stresses [27]. Three transcripts down-regulated by $\mathrm{H}$ and $\mathrm{L}$, in both varieties, share the $\mathrm{C} 3 \mathrm{HC} 4$ type $\mathrm{Zn}$-finger (RING-finger) domain. C3HC4 is one of the TF sub-families up-regulated in response to light stress and has been defined as a specific ROS marker [28]. However, studies in grapevine have already shown an opposite response (down-regulation under drought and heat [8], and under high light [18]). The present work further confirms these findings in both studied varieties. Nudix hydrolases are ubiquitous enzymes that hydrolyse a large variety of nucleoside diphosphate derivatives $[29,30]$. The protein NUDT17 has been associated with biotic stress in Arabidopsis thaliana [31] and recently, a cytoplasm RhNudix1was found to catalyse a step in the pathway for scent monoterpenesin in roses [32]. Cell wall genes, namely those coding for expansins, pectinesterases, and endoxyloglucan transferases are usually down-regulated in typical abiotic stress responses when cell division and growth are hindered [33], and thus it is not surprising to find a $ß$-expansin among the genes down-regulated in both varieties and in two different abiotic stresses ( $\mathrm{L}$ and $\mathrm{H}$ ).

The varieties reacted differently in the field experiment. In fact, conversely to IS and in agreement with the PCA plot, the total number of differentially expressed genes was slightly higher in TN (1951) than in TR (1622) field plants (Fig. 3c), 311 up-regulated and 228 down-regulated under NI in both varieties (Fig. 3d). The results obtained indicate that, under the same field conditions each variety expressed specific sets of genes, whereas only a minor proportion of the stress response was shared. However, when transcripts responsive to the field NI treatment were directly compared to the IS responsive ones, the results evidenced a variety-dependent response (Additional file 4). In Trincadeira, although the number of $\mathrm{W}$ and L-responsive genes was higher than in NI, only a small proportion of IS and NI-responsive genes overlapped (Additional file $4 \mathrm{a}-\mathrm{c}$ ). Focusing on TN plants we observe a distinct behaviour: a lower number of IS-responsive genes but a higher proportion overlapping with the NI responsive ones (Additional file 4d-f). A species-associated response was recently described for desiccated leaves of three Vitis species, which differed in activation of ABA and ethylene signalling pathways according to their sensitivity or tolerance to drought [34]. A variety-associated response has been previously described for metabolite accumulation in Cabernet Sauvignon and Sangiovese berries [35]. Furthermore a transcriptomic varietal specificity comprising 180 novel genes not found in the already sequenced grapevine varieties was identified in the Italian cv. Corvina [36].

\section{Distribution of differentially expressed genes into functional categories is similar in both varieties}

Treatment-responsive transcripts were assigned into seven functional categories (Cellular process, Metabolism, Regulation, Response to stimulus, Signalling, Transport, and Unknown) according to GrapeGen 12x_v2.1 annotation (http://genomes.cribi.unipd.it/grape/) (Additional file 5). In Trincadeira (TR) under individual stress (IS), most functional categories presented more down- than upregulated genes. Exceptionally, Response to stimulus and Regulation (in W) and Signalling and Transport (in L) showed more up-regulated genes. Additionally, in $\mathrm{H}$ most genes were down-regulated in all functional categories (Additional file 5). These results differ from a previous study with the grapevine variety Aragonez (syn Tempranillo) in equivalent IS conditions, where $\mathrm{H}$ offered a higher amount of responsive genes as compared to W [8]. With few exceptions, each stress treatment caused a higher number of down-regulated genes in all functional categories, which differs significantly from other studies in which up-regulated genes were prevalent [8, 37]. Metabolism was the category including the highest number of down-regulated genes (Additional file 5), consequently metabolism breakdown dominated plant responses.

Despite the fact that TN presented fewer responsive genes in controlled IS conditions when compared with TR (Fig. 3B), the percentage of genes in three relevant functional categories, Response to Stimulus (stress 
response), Signalling (hormone and other signalling pathways) and Regulation (transcription factors) was compared between the two varieties (Additional file 6). The functional annotation of up-regulated genes shows that water stress (W) gave the highest percentage in Regulation category in TN and in Signalling category in $\mathrm{TR}$, a contrasting response to the IS treatments between the two varieties. Conversely, Trincadeira under high light $(\mathrm{L})$ and heat $(\mathrm{H})$ showed a higher percentage of upregulated genes in Regulation. However, both varieties had similar percentages of down-regulated genes upon all stresses (Additional file 6). As a whole, different quantitative and qualitative responses to the IS treatments were observed between the two varieties. Trincadeira activated a greater transcriptome reprogramming than TN to cope with the same environmental conditions, namely investing more in enzymes and metabolites of the antioxidative system as reported for the same varieties under heat stress [13]. The smallest reprogramming in TN is enough to react more rapidly and efficiently than $\mathrm{TN}$, confirming the better adaptability of this variety as before [12]. However, when comparing TN and TR under field NI conditions, the percentage of responsive genes annotated in the selected categories tended to be higher than for IS in both varieties, with the exception of down-regulated genes after $\mathrm{H}$ stress (Additional file 6). These results evidence the contrasting responses of both varieties between controlled and field conditions.

\section{Stress-responsive genes showing the greatest magnitude of change are variety-specific}

For each variety, circa 30 genes most up- (Table 2) or down-regulated (Table 3), based on the expression fold change (treatment/control) were selected from the microarray. Ten were assigned to each individual stress (IS) treatment (five up and five down-regulated). This selection included genes without annotation (Unknown category in GrapegenDB) when homologous transcripts were identified at NCBI database (http://www.ncbi.nlm.nih.gov/) (Tables 2 and 3; Additional file 7).

When Trincadeira (TR) plants were subjected to water stress (W) (Table 2) the gene VviEXLB4, an expansin precursor [26] with $\log _{2}$ (fold change) of seven was the most up-regulated gene (Table 2; Additional files 7 and 8 ). This gene family has been demonstrated to be highly expressed during the initial phase of drought stress in Arabidopsis [38, 39]. Conversely to TR, VviEXLB4 was not significantly induced in $\mathrm{TN}$, further evidence for the distinct response of this variety to drought. Other greatly up-regulated genes in TR under $\mathrm{W}$ include VviMYBC2-L4 [40, 41] and HSP2O both reported to be involved in several abiotic stresses including drought and heat $[13,29,37]$. In TR the five most up-regulated genes after light stress (L) were OST1, ProOx, CXE, ZFC, and ELIP1 (Table 2; Additional files 7 and 8). OST1 belongs to the serine threonine-protein kinase protein class and is involved in response to several abiotic stresses [42-44] and CXE codes for a protein with carboxylesterase activity with a role in plant detoxication [45]. In TR under heat stress $(\mathrm{H})$ four of the five most up-regulated genes code for small heat shock proteins (HSPs) (Table 2 and Additional file 7) confirming this family as the most important class of genes responding to heat stress $[8,13]$. The fifth gene, GolS1, belongs to the galactinol synthase family previously described as responsive to drought and dehydration [46, 47], as well as, induced by heat in grapevine berries $[48,49]$. Regarding the most down-regulated genes (Table 3), in TR under W stress, two genes coding for cell wall remodelling enzyme were significantly repressed: the expansin precursor (VviEXPA18, conversely to the up-regulated VviEXLB4 referred to above) and a polygalacturonase gene (PG2). Among the downregulated transcripts after $\mathrm{W}$ stress were a lipase, a $C M L$ and a gene coding for a thiazole biosynthetic enzyme (THI1) (Additional file 7). This gene was described as playing an important role in mitochondrial DNA damage tolerance, [50-52], membrane modulation [53], and as being over-expressed under low temperature conditions [37]. The fact that our plants were kept at room temperature $\left(22-25{ }^{\circ} \mathrm{C}\right)$ except in $\mathrm{H}$ treatment, can explain the down-regulation of this gene after the $\mathrm{H}$ of IS treatment. Under L stress, the most down-regulated genes were assigned to four functional categories: Unknown (BAP2), Metabolism (ASP and NUDT17), Signalling (Clmd) and Regulation (ERF5-1) [54, 55] (Additional file 7). Clmd codes for calmodulin, involved in signaling pathways through the modulation of the activity of other enzymes [56]. Under $\mathrm{H}$ the most down-regulated genes include the ABA hydrolase CYP707A1, one ethylene responsive factor $(E R F-1)$, a zinc finger ZAT10 (STZ), one cytosolic class-I small heat-shock protein (HSP18) and WRKY46 (Additional file 7). In field NI conditions (F) the most down-regulated genes in TR were within the Metabolism functional category, two serine carboxypeptidase (SCPL7_scpl18 and scpl16_scpl17), one chalcone synthase (TT4), a gibberellin oxidase (GA20OX1) and a fifth transcript of the Transport functional category that codes a $14 \mathrm{kDa}$ proline-rich protein also down-regulated in Touriga Nacional field NI (Additional file 7).

Focusing on Touriga Nacional (TN) plants, due to the low magnitude of change obtained in the microarray across the several ISs, some of the five most up (Table 2), or down regulated genes (Table 3) have $\log _{2}$ (fold change) $<2$. Within the four most upregulated genes is a late embryogenesis abundant protein transcript (LEA) which is involved in dehydration and desiccation [57, 58]. Under L, the five most up- 
Table 2 Up-regulated genes

\begin{tabular}{|c|c|c|c|c|}
\hline Variety/Treatment & Name & $\log _{2}$ & ID & Annotation \\
\hline TR_W & VviEXLB4 & 7.24 & VIT_200s1455g00010 & expansin-like b1 \\
\hline TR_W & $I E a P^{a}$ & 5.02 & VIT_205s0020g00840 & late embryogenesis abundant protein $\mathrm{d}$-29-like \\
\hline TR_W & VviMYBC2-L4 & 4.02 & VIT_217s0000g02650 & transcription repressor MYB4-like \\
\hline TR_W & HSP2O & 4.39 & VIT_209s0002g06790 & hsp20-like chaperone \\
\hline TR_W & FMT & 4.21 & VIT_210s0003g00480 & flavonoid o-methyltransferase related \\
\hline TR_L & OST1 & 3.63 & VIT_202s0236g00130 & serine threonine-protein kinase \\
\hline TR_L & ProOx $^{\mathrm{a}}$ & 3.55 & VIT_214s0083g00520 & proline dehydrogenase \\
\hline TR_L & $C X E^{\mathrm{a}}$ & 3.52 & VIT_208s0032g00700 & probable carboxylesterase 15 \\
\hline TR_L & ZFC & 3.19 & VIT_216s0098g00360 & zinc finger protein constans-like protein \\
\hline TR_L & $\underline{\text { ELIP1 }}$ & 2.96 & VIT_205s0020g04110 & early light-inducible protein \\
\hline TR_H & HSP21 & 5.56 & VIT_216s0098g01060 & chloroplast low molecular weight heat shock protein \\
\hline TR_H & mHSP23 & 4.73 & VIT_202s0154g00490 & mitochondrial small heat shock protein \\
\hline TR_H & Gols1 & 4.64 & VIT_207s0005g 01980 & galactinol synthase \\
\hline TR_H & HSP18 & 4.47 & VIT_213s0019g03000 & $18.1 \mathrm{kDa}$ class i heat shock protein HSP18 \\
\hline TR_H & HSP2O & 4.39 & VIT_209s0002g06790 & hsp20-like chaperone \\
\hline FTR & $P P P^{a}$ & 4.90 & XM_010667183 & pentatricopeptide repeat-containing protein \\
\hline FTR & $P D P^{a}$ & 4.43 & VIT_201s0127g00560 & probable nucleoredoxin 1-like \\
\hline FTR & HSP17II & 4.01 & VIT_204s0008g01590 & $17.3 \mathrm{kDa}$ class ii heat shock protein \\
\hline FTR & HSP2O & 3.99 & VIT_209s0002g06790 & hsp20-like chaperone \\
\hline FTR & CHSP21 & 5.56 & VIT_216s0098go1060 & chloroplast low molecular weight heat shock protein \\
\hline TN_W & E12A11 & 1.82 & VIT_200s0203g00080 & protein mother of $\mathrm{ft}$ and $\mathrm{tf} 1$ \\
\hline TN_W & LEA & 1.81 & VIT_203s0038g04390 & late embryogenesis abundant \\
\hline TN_W & HAl1_HAl3 & 1.78 & VIT_206s0004g05460 & protein phosphatase $2 \mathrm{c}$ \\
\hline TN_W & Lipase $^{a}$ & 1.32 & XM_002265963 & GDSL esterase/lipase \\
\hline TN_L & $\underline{\text { PRP-l }}^{a}$ & 3.09 & VIT_202s0154g00320 & $14 \mathrm{kDa}$ proline-rich protein \\
\hline TN_L & NitTrans $^{\mathrm{a}}$ & 2.61 & VIT_217s0000g09470 & nitrate transmembrane transporter \\
\hline TN_L & $P R P-\|^{\mathrm{a}}$ & 1.89 & VIT_202s0154g00300 & $14 \mathrm{kDa}$ proline-rich protein \\
\hline TN_L & GLP4 & 1.86 & VIT_217s0000g05360 & rhicadhesin receptor \\
\hline TN_L & GA2OX8 & 1.79 & VIT_210s0116g00410 & gibberellin 20-oxidase \\
\hline TN_H & CML44 & 3.31 & XM_002285850 & probable calcium-binding protein CML44 \\
\hline TN_H & ELIP1 & 2.96 & VIT_205s0020g04110 & early light-inducible protein \\
\hline TN_H & Gols1 & 2.64 & VIT_207s0005g01980 & galactinol synthase \\
\hline TN_H & $D n a\rfloor^{a}$ & 2.52 & VIT_214s0060g01490 & heat shock protein binding \\
\hline TN_H & ProKin $^{\mathrm{a}}$ & 2.19 & VIT_218s0166g00010 & probable LRR receptor-like serine/threonine-protein kinase \\
\hline FTN & $P R P 1^{\mathrm{a}}$ & 3.58 & VIT_211s0052g01650 & pathogenesis-related protein \\
\hline FTN & BGLU17 & 4.48 & VIT_213s0064g01660 & beta-glucosidase 13-like \\
\hline FTN & FTSH6 & 3.76 & VIT_214s0108g00590 & cell division protease ftsh- 6 \\
\hline FTN & $\mathrm{CoCHA}$ & 3.66 & VIT_203s0038g02110 & chaperone protein dnaj chloroplastic-like \\
\hline FTN & Ankyrin $^{\mathrm{a}}$ & 3.62 & VIT_205s0029g01410 & ankyrin repeat-containing protein \\
\hline
\end{tabular}

\footnotetext{
${ }^{a}$ Genes whose short name was attributed by the authors to facilitate writing. The five most up-regulated genes in Trincadeira (TR) and Touriga Nacional (TN) individual stress treatments (IS): Water deficit (W); High light (L); Heat (H); and Field: Trincadeira (FTR), Touriga Nacional (FTN). Name, expression value (in log 2 gene expression, ID from 12x_v2.1 (http://genomes.cribi.unipd.it/grape/) or NCBI accession. Genes highlighted in bold represent genes that are shared between treatments and genes highlighted in underline represent genes shared between varieties, in Table 2 and between Table 2 and 3
} 
Table 3 Down-regulated genes

\begin{tabular}{|c|c|c|c|c|}
\hline Variety/Treatment & Name & $\log _{2}$ & ID & Annotation \\
\hline$\overline{T R \_W}$ & $\operatorname{LipGDSL}^{\mathrm{a}}$ & -3.95 & XM_002272934 & GDSL esterase/lipase \\
\hline TR_W & VVIEXPA18 & -3.92 & VIT_217s0053g00990 & expansin \\
\hline TR_W & $C M L^{\mathrm{a}}$ & -3.73 & VIT_218s0001g01630 & ef hand family protein \\
\hline TR_W & THI1 & -3.49 & VIT_210s0116g00530 & thiazole biosynthetic enzyme \\
\hline TR_W & $P G 2$ & -3.47 & VIT_201s0127g00850 & probable polygalacturonase non-catalytic subunit jp650-like \\
\hline TR_L & $\mathrm{Clmd}^{\mathrm{a}}$ & -3.58 & XM_002277463 & putative calcium-binding protein CML19 \\
\hline TR_L & ERF5-1 & -3.58 & VIT_216s0013g00950 & ethylene-responsive transcription factor 5 \\
\hline TR_L & NUDT17 & -3.56 & VIT_217s0000g02050 & Nudix hydrolase 17 \\
\hline TR_L & $B A P 2^{a}$ & -3.19 & VIT_215s0048g02070 & BON1-associated protein (BAP2) \\
\hline TR_L & ASP & -3.17 & VIT_218s0001g07340 & aspartyl protease \\
\hline TR_H & $S T Z$ & -4.38 & VIT_218s0001g09230 & zinc finger protein ZAT10-like \\
\hline TR_H & WRKY46 & -4.15 & VIT_215s0046g01140 & WRKY transcription factor 46 \\
\hline TR_H & SRS2 & -3.87 & VIT_216s0013g00300 & ATP-dependent DNA helicase \\
\hline TR_H & ERF-1 & -3.86 & VIT_202s0234g00130 & ethylene-responsive transcription factor 1a \\
\hline TR_H & CYP707A1 & -3.85 & VIT_202s0087g00710 & abscisic acid 8-hydroxylase \\
\hline FTR & SCPL7_SCPL18 & -4.04 & VIT_203s0091g01290 & serine carboxypeptidase-like 18 -like \\
\hline FTR & $\underline{\text { PRP-I }}^{\mathrm{a}}$ & -3.64 & VIT_202s0154g00320 & $14 \mathrm{kDa}$ proline-rich protein \\
\hline FTR & GA200X1 & -3.32 & VIT_216s0022g02310 & gibberellin 20-oxidase \\
\hline FTR & TT4 & -3.32 & VIT_205s0136g00260 & Chalcone synthase \\
\hline FTR & SCPL16_SCPL17 & -3.18 & VIT_203s0088g00260 & serine carboxypeptidase-like 18 -like \\
\hline TN_W & THI1 & -3.49 & VIT_210s0116g00530 & thiazole biosynthetic enzyme \\
\hline TN_W & Pepd ${ }^{a}$ & -1.54 & VIT_218s0001g00510 & prolyl oligopeptidase-like protein \\
\hline TN_L & HSP17 & -4.83 & VIT_213s0019g02760 & $17 \mathrm{kDa}$ class i heat shock protein \\
\hline TN_L & ERF5-1 & -3.62 & VIT_216s0013g00950 & ethylene-responsive transcription factor 5 \\
\hline TN_L & HSP17II & -3.43 & VIT_204s0008g01500 & $17 \mathrm{kDa}$ class ii heat shock protein \\
\hline TN_L & ${\underline{C l m d^{a}}}^{a}$ & -3.58 & XM_002277463 & putative calcium-binding protein CML19 \\
\hline TN_L & HSP18 & -3.41 & VIT_213s0019g02770 & 18 kDa class i heat shock protein \\
\hline TN_H & $S s P^{a}$ & -4.36 & VIT_200s0586g00030 & stem-specific protein \\
\hline TN_H & XTR6 & -3.30 & VIT_211s0052g01260 & probable xyloglucan endotransglucosylase hydrolase protein \\
\hline TN_H & $J A Z 8$ & -3.16 & VIT_210s0003g03810 & protein tify 5 a-like \\
\hline TN_H & NUDT17 & -3.56 & VIT_217s0000g02050 & Nudix hydrolase 17 \\
\hline TN_H & VviVQ3 & -2.87 & VIT_202s0025g01280 & WRKY transcription factor 41 \\
\hline FTN & $\underline{\text { PRP-1 }}^{a}$ & -3.64 & VIT_202s0154g00320 & $14 \mathrm{kDa}$ proline-rich protein \\
\hline FTN & PYL4 & -3.41 & VIT_213s0067g01940 & abscisic acid receptor pyl4 \\
\hline FTN & $P R P-36^{\mathrm{a}}$ & -3.37 & XM_003631687 & $36.4 \mathrm{kDa}$ proline-rich protein \\
\hline FTN & PME61 & -3.17 & VIT_205s0062g01160 & pectinesterase family protein \\
\hline FTN & ZIP2 & -3.16 & VIT_206s0004g05070 & zinc transporter \\
\hline
\end{tabular}

${ }^{a}$ Genes whose short name was attributed by the authors to facilitate writing. The five most down-regulated genes in Trincadeira (TR) and Touriga Nacional (TN) individual stress treatments (IS): Water deficit (W); High light radiation (L); Heat (H); and in the Field: Trincadeira (FTR), Touriga Nacional (FTN). Name, expression value (in $\log _{2}$ gene expression), ID from 12x_v2.1 (http://genomes.cribi.unipd.it/grape/) or NCBI accession. Genes highlighted in bold represent genes that are shared between treatments and genes highlighted in underline represent genes shared between varieties, in Table 3 and between Table 2 and 3

regulated genes belong to the Transport or Metabolism (Primary and Secondary) functional categories (Additional file 7). Under $\mathrm{H}$, the induced genes have all $\log _{2}$ (fold change) $>2, C M L 44$, ELIP1 (as in TR L) and GolS1 (as in TR H), the HSP gene DnaJ and
ProKin, a gene coding a protein kinase (Additional file 7). Of note is the absence of small HSPs.

Considering the TN down-regulated genes (Table 3) in water (W) stress, only two transcripts fulfilled the established criterion, one being THI1, also a down-regulated 
gene in TR after W. It is interesting to note that the most down-regulated genes found after light (L) are three HSPs, an ERF and a calcium-binding protein (Clmd), both in common with TR L. Under $\mathrm{H}$ the most down-regulated genes include XTR6 a gene for a remodelling cell wall protein, the gene for the same Nudix hydrolase (NUDT17) referred to above as downregulated in TR under L stress, and the gene VviVQ3, coding for a WRKY-interacting factor [23], that may be implicated in the response to biotic stress in Arabidopsis [59]. Although this WRKY gene isoform was downregulated in TN under $\mathrm{H}$, other $V$. vinifera cv. Aragonez WRKY transcription factors responded to drought and heat stress [8]. In $\mathrm{TN}$, the most-responsive genes to the NI field treatment showed changes in expression ranging between 3.6 and $4.5 \log _{2}$ (fold change). The most upregulated genes were the biotic stress responsive proteins (PRP1) and ankyrin repeats protein [60] a $\beta$ glucosidase (PHA) a cell division protease (FTSH6) and a co-chaperone HSP (CoCHA). The five most downregulated genes code for an ABA receptor (PYL4), a pectinesterase, a $\mathrm{Zn}$ transporter and two proline-rich proteins (PRP-I and PRP-36) (Additional file 7). Curiously, $(P R P-I)$ was up-regulated after $\mathrm{L}$ stress as referred above.

\section{Array validation by RT-qPCR}

The expression of the five most up- and down-regulated genes selected from the microarray (Tables 2 and 3) were quantified by RT-qPCR in individual stress (IS) and field (F) samples (Additional file 8) in order to assess the correlation between both methods. The obtained correlation coefficients were above 0.9 except for Touriga Nacional (TN) under water deficit (W) stress $(r=0.75)$ and high light $(\mathrm{L})$ stress $(r=0.57)$ (Additional file 9). In general expression trends measured by microarray and RT-qPCR were the same with few exceptions. Although in Trincadeira (TR) VviMYBC2-L4 was up-regulated by $\mathrm{W}$ in the array, it was down-regulated in the RT-qPCR. The four up-regulated transcripts in TN W were downregulated in the RT-qPCR (Additional file 8). One possible explanation regarding the discrepancy of these up-regulated genes is the extremely low $\log _{2}$ (fold change) values, just over the limit value, of TN W genes, which barely fulfilled the established criteria.

\section{Except for drought, less transcriptome reprogramming is activated in Touriga Nacional under combined abiotic stresses}

The expression of the genes presented in Tables 2 and 3 was analysed in the leaf samples collected under combined stress treatments [water;high light (WL), water; heat (WH), high light;heat (LH) and water;high light;heat (WLH)] by RT-qPCR To ascertain the genomic response of field (F) NI samples, Trincadeira (TR) and Touriga Nacional (TN) leaves were probed as well (Fig. 4 and 5). The actual experimental approach is rather unique so few results are available so far, only allowing a scarce comparison with our data. Considering $\mathrm{TR}$, the correlation between the values in the respective ISs (W and L) and the combined WL was 0.81. The combined water;high light treatment attenuated the response observed in $\mathrm{W}$ for several genes (VviEXLB4, IEaP, HSP20, FMT, THI1) indicating that water responsive genes, including those previously reported $[9,13]$, have their expression inversed when $\mathrm{W}$ and $\mathrm{L}$ stresses are imposed simultaneously (Fig. 4a). In contrast WL enhanced the response of several $\mathrm{L}$ up-regulated genes (OST1, CXE, ZFC) (Fig. 4a). Among the down-regulated genes in TR analysed by RT-qPCR, after WL stresses, only thiazole biosynthetic enzyme (THI1) changed its expression pattern. However, down-regulation of THI1 seems to be countered by the simultaneous imposition of WL, becoming up-regulated. THI1 response to W was also mitigated when $\mathrm{W}$ and $\mathrm{H}$ were combined (Fig. 4b), similarly to the response of $\mathrm{H}$ down-regulated genes (WRKY, SRS2, ERF-1 and CYP707A1), although the overall correlation was very high, 0.9. Under LH (Fig. 4c) the response of three L-responsive genes (OST1, CXE and Clmd) and only one H-responsive gene (the $\mathrm{H}$ down-regulated ERF-1) were also significantly reverted. Similarly, a broad transcriptome inhibition after drought combined with heat had been shown before in Arabidopsis thaliana plants [9, 61], indicating a reversal of drought responses by heat. The lower downregulation of ERF-1 and Clmd in the combined $\mathrm{LH}$ might reveal more about their functions and interaction regarding environmental responses (see above). Of note is V. pseudoreticulata ERF-1 which showed contrasting transcriptional response to different abiotic stress treatments [62]. The low variations in Trincadeira genes after LH treatment made their overall correlation the highest of the tested combined stresses $(r=0.95)$ (Fig. 4c). This suggests most of the responses to $\mathrm{L}$ and $\mathrm{H}$ in TR are independent or similar as reported for Arabidopsis, even though combined high light and heat response only correlated strongly with the heat response [63]. When the three individual stresses were combined (WLH) (Fig. 4d) the expression of most $\mathrm{W}$-responsive genes was significantly attenuated. High light $(\mathrm{L})$ and heat $(\mathrm{H})$ up-regulated genes showed the same profile under WLH. Where a lower response of down-regulated genes under IS was generally observed, the overall correlation was still high, 0.92 (Fig. 4d). In TR field (Fig. 4e) samples, many Wresponsive genes did not amplify, while the response of most other IS-selected genes decreased with exception of the $\mathrm{W}$ and $\mathrm{L}$ down-regulated $C M L$, and $A S P$, respectively, 


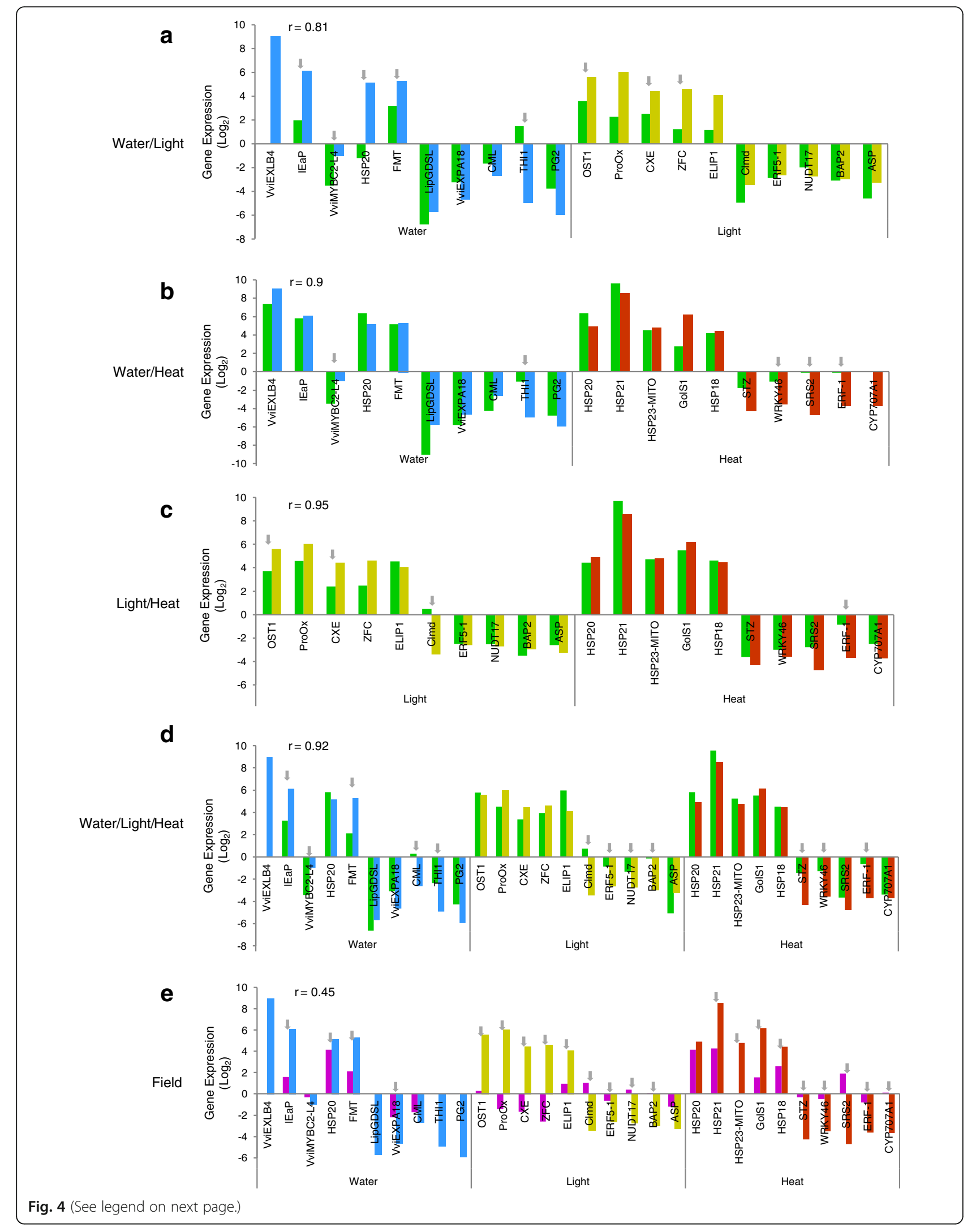




\section{(See figure on previous page.)}

Fig. 4 Gene expression response upon combined abiotic stresses in Trincadeira. Gene expression analysed by RT-qPCR for the five most up- and down-regulated genes when ISs are combined: water:high light (a); water:heat (b); high light:heat (c); water:high light:heat (d); field conditions (e), Colour-code for gene expression according to stress response: water deficit (blue); high light (yellow); heat stress (red); the combination of water deficit, high light and/or heat (dark green) and genes expressed in the field experiment (purple). Grey arrows represent significant statistical differences in gene expression between individual and combined stress treatments under controlled conditions or field experiment, $p<0.05$. Log $_{2}$ gene expression was normalized to control conditions. Gene annotation as in Tables 1 and 2. r, correlation coefficient

and the consistently up-regulated HSP2O upon H stress, a low correlation of 0.45 was obtained.

Considering Touriga Nacional (TN), when W and L stresses were combined (Fig. 5a) the expression of Wand L-responsive genes changed significantly. Downregulation of THI1 and Pepd by W was significantly attenuated and L-responsive transcripts exhibited a higher variation. The up-regulated response of NitTrans and HSP17 was enhanced under WL, while the response of four other $\mathrm{L}$ up-regulated genes was attenuated or reversed resulting in $r=0.58$ (Fig. 5a). WH combination gave rise to an even higher variation in the $\mathrm{W}$ responsive transcripts (Fig. 5b). Considering $\mathrm{H}$-responsive transcripts, the expression of two up-regulated genes (GolS1 and $D n a J$ ) was enhanced while the down-regulation of $X T R 6$ and JAZ8 was attenuated. However, the $\mathrm{r}$ value in WH was 0.75 (Fig. 5b). Gene expression after LH (Fig. 5c) was consistent with the respective individual stress RT-qPCR values with an $r=0.85$, the highest in TN stress combinations (Fig. 5c). Touriga Nacional results confirm that responses to $\mathrm{L}$ and $\mathrm{H}$ follow the same trend as in TR (above) and Arabidopsis [63]. After WLH treatment (Fig. $5 \mathrm{~d}$ ), all the $\mathrm{W}$ and the majority of the $\mathrm{L}$ response genes exhibit significantly different expression profiles, while $\mathrm{H}$-responsive genes maintained the same trend. The variation in $\mathrm{W}$ and $\mathrm{L}$ transcripts caused a low r, 0.35 (Fig. 5d). In TN field NI samples, when the IS transcripts were tested most transcripts did not amplify or their expression was significantly different from IS gene expression, resulting in a very low $\mathrm{r}$ value, 0.18 (Fig. 5e).

Our results confirm the limited accuracy of extrapolating the effects of individual, or even combined, abiotic stress in controlled conditions to actual plant growth and functioning [10]. Grafted and well rooted grapevine plants growing in the field or potted plants obtained from cuttings in controlled conditions certainly respond differently to environmental changes. Taken together, the above results show how complex the relationship is between gene expression and the environmental setting. However, the experimental set up applied to two genotypes can elucidate unique transcriptomic responses associated with particular tolerance mechanisms after each stress, per variety. Furthermore, our results also show that the grapevine capacity to manage abiotic stress response is intrinsically variety-linked. While TR responded clearly to IS treatments and that response was maintained under combined ISs, in TN, the responses varied a great deal under IS combination, especially when $\mathrm{W}$ was involved. This seems to confirm the higher tolerance of $\mathrm{TN}$, with less transcriptome reprogramming except when water deficit is involved $[8,13]$.

\section{Transposable elements and grapevine abiotic stress responses}

It is known that most genomes comprise transposable elements (TEs) whose activation by stress suggests their role as key players in genome plasticity to survive in adverse environments [64, 65]. Grapevine is not an exception with about one fifth of its genome comprising this type of repeats [66]. To gain more information about the Vitis transposable sequences still not characterized, we queried those sequences present in the Unknown functional category against a transposable elements database (http://www.girinst.org/). In this query we obtained homologies for $20 \%$ of the sequences with known transposable elements (Additional file 10: Figure S1) and we found that TEs are represented within Trincadeira (TR) and Touriga Nacional (TN) stress-responsive genes. The percentage of matches ranged from 28 to $40 \%$ in TR and from $25 \%$ to $36 \%$ in TN (Additional file 10: Table S1). Within TEs, two classes are predominant, DNA transposons and LTR retrotransposons (Additional file 10: Tables S2 and S3).

Clustering the profiles of the expressed TEs using the k-means algorithm resulted in 8 groups in TR (Additional file 10: Figure S2) and 7 groups in TN (Additional file 10: Figure S3). These profiles showed that in Trincadeira W stress, $58.8 \%$ of the TEs were down-regulated and $41.2 \%$ were up-regulated while after $\mathrm{L}$ more or less the same number of up and downregulated TEs was obtained. Strikingly, monitoring TEs in field Trincadeira samples (FTR) revealed a burst of activity with $70 \%$ of the TEs up-regulated. The comparison between TR and TN under IS was somewhat compromised given the generally low activity in the latter. However, as in TR, 58.7 \% TEs in field Touriga Nacional (FTN) showed up-regulation. Although detecting TEs transcripts does not necessary mean that they are transposing, we do not rule out the stress-induced TE mobility hypothesis put forward for other species [67, 68] favouring the genetic variability eventually useful for 


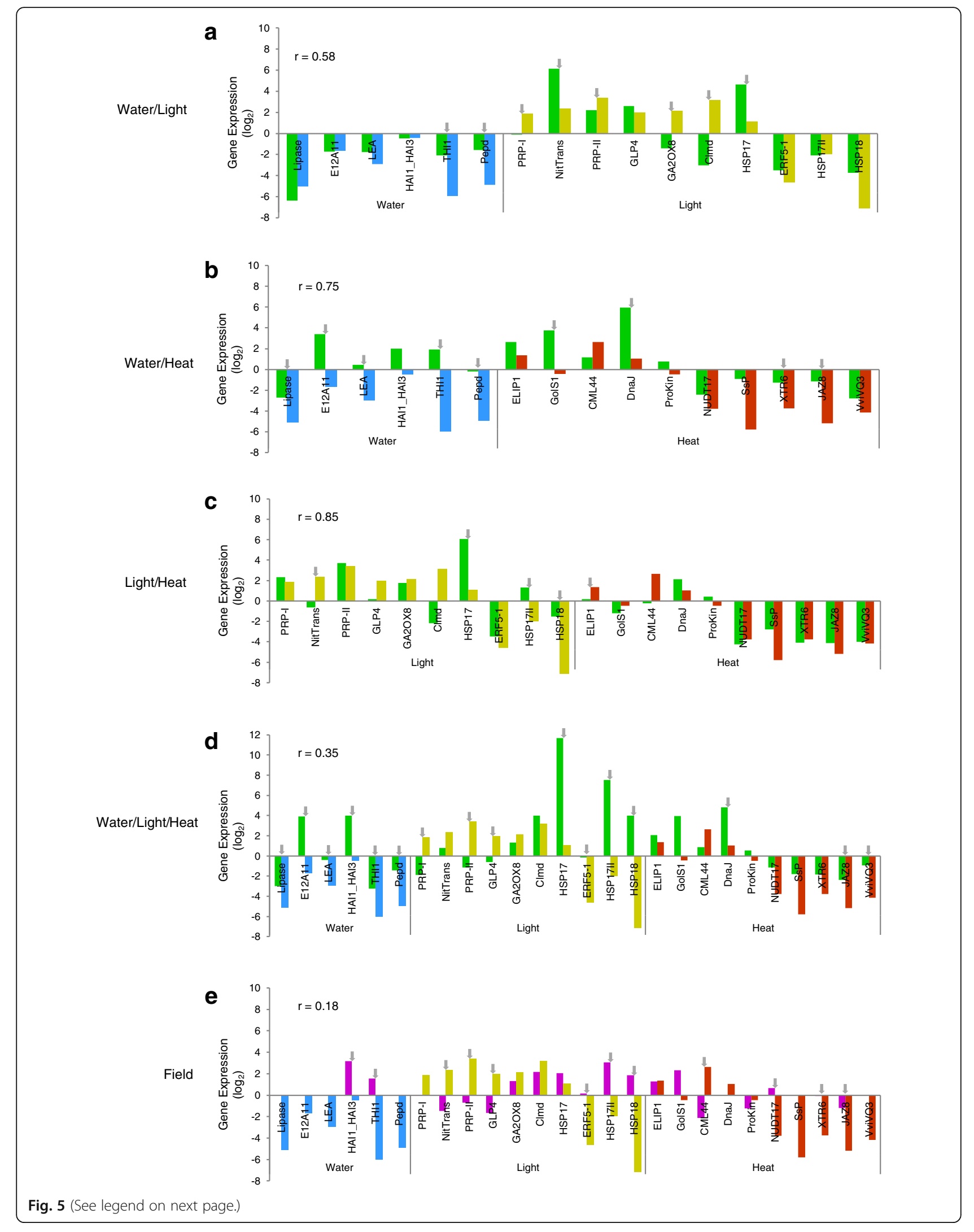


(See figure on previous page.)

Fig. 5 Gene expression response upon combined abiotic stresses in Touriga Nacional. Gene expression analysed by RT-qPCR for the five most up- and down-regulated genes when IS are combined: water:high light (a); water:heat (b); light:heat (c); water:high light:heat (d); field conditions (e). Colour-code for gene expression according to stress response: water deficit (blue); light stress (yellow); heat stress (red); the combination of water deficit, light and/or heat (dark green) and genes expressed in the field experiment (purple). Grey arrows represent significant statistical differences in gene expression between individual and combined treatments under controlled conditions or field experiment, $p<0.05$. Log $_{2}$ fold change was normalized to control conditions. Gene annotation as in Tables 1 and 2. r, correlation coefficient

adaption to a changeable environment [65, 69]. Our data revealed several fragments of TEs (Additional file 10:Figures S4 and S5) that could partially contribute to the plasticity of individual genes, for instance, through new introns, exons, or chimeric genes. These are not rare events, since a high proportion of Angiosperm genes harbour TEs, as referred for rice where more than $10 \%$ of transcripts are reported to contain TEs [70]. We also performed an expression profile analysis of the TEs common to the applied treatments (Additional file 10: Figure S6). The results revealed changes in the expression of some TEs, pointing to stress-induced TE activity, a result that can explain the adaptation to environmental challenges $[69,71]$. The mechanisms involved in activation and repression of TEs in plants are still not clearly understood and are beginning to be unravelled. Our data show that TEs changed expression in a stress-specific manner, suggesting a potential role of TEs in grapevine stress response and adaptation, deserving further investigation.

\section{Conclusions}

Microarray data were obtained from leaves of two grapevine varieties commonly used in Portugal for wine making, Touriga Nacional (TN) and Trincadeira (TR). They were subjected to individual abiotic stress treatments in growth room controlled conditions and in agronomic field conditions, and confirmed TN as less responsive to abiotic stress imposed in the growth room than TR. Regarding the combination of individual abiotic stresses, the expression of selected genes was as expected from the individual stresses (ISs), with only a few genes exhibiting statistically different levels of expression, pointing to antagonist or in lower frequency synergistic interplay between the ISs. Only under the field environmental constraint, when both varieties were compared for full irrigation (FI) and no irrigation (NI) did Touriga Nacional exhibit an unequivocal transcriptomic response. This result may indicate that TN has a different threshold for the level of stress it can withstand before triggering a response. A high number of differentially expressed genes were assigned to the Unknown category [21]. It cannot be excluded that several key genes for grapevine stress response are still with non-described function. An interesting fact was that $20 \%$ of the manually re-annotated Unknown category genes were assigned to mobile elements, a significant class in any genome, including grapevine [66]. Finally, the results allow the conclusions: 1) experiments in controlled conditions still remain a useful resource to study the effect of single stresses although correlations to field condition results must be cautious; 2) varieties of the economically important crop grapevine, even when cultivated in common areas under extreme environmental conditions, can display gene expression profiles evidencing a considerable intra-species diversity of responses to the environment; 3 ) mobile elements are well represented in grapevine stress-responsive transcriptome but their response to abiotic stress remains mostly unknown, deserving to be studied in depth.

\section{Methods \\ Growth room plant material and stress treatments}

Cuttings from pruned wood of selected Vitis vinifera L. plants of the varieties Touriga Nacional (TN) and Trincadeira (TR) were grown in $3 \mathrm{l}$ pots in the growth room under the following controlled conditions: $200 \mu \mathrm{mol}$ quanta $\mathrm{m}^{-2} \cdot \mathrm{s}^{-1}$ irradiance, $16 \mathrm{~h}$ light $/ 8 \mathrm{~h}$ dark photoperiod, temperature of $25{ }^{\circ} \mathrm{C}$ day/ $23{ }^{\circ} \mathrm{C}$ night and wellwatered with nutrient solution [72]. The growth room has $72 \mathrm{~m} 2$ and is adapted to provide controlled conditions of light and temperature.

Individual stresses (ISs) were applied when shoots were 50 to $60 \mathrm{~cm}$ high (after circa four months from cuttings planting) always in the middle of the light period, so that sampling took place shortly after that period. The treatments applied were: $\mathrm{W}$ - stop irrigation until the pre-dawn leaf water potential $\left(\Psi_{\mathrm{w}}\right)$ was $-0.9 \mathrm{MPa}$, value that is consistent with a severe water stress [73]; high light (L) $-1 \mathrm{~h}$ at $2,000 \mu \mathrm{mol} \cdot \mathrm{m} 2 \cdot \mathrm{s}-1$; heat $(\mathrm{H})-1 \mathrm{~h}$ at $42{ }^{\circ} \mathrm{C}$ (temperature measured at the surface of the leaf) provided by a homogenous heat source; WL - a combination of both $\mathrm{L}$ and W; WH - a combination of both $\mathrm{W}$ and $\mathrm{H} ; \mathrm{LH}-$ a combination of $\mathrm{L}$ and $\mathrm{H} ; \mathrm{WLH}-\mathrm{a}$ combination of W, L and $\mathrm{H}$. $\Psi_{\mathrm{W}}$ was measured with a pressure chamber, Model 600, PMS Instruments Company (Albany, OR). Samples consisted of the first, second and third totally expanded leaves from the shoot apex and were taken $1 \mathrm{~h}$ after the start of the stress treatment together with control samples (or, in the case of WS, when the pre-dawn leaf $\Psi_{\mathrm{w}}$ reached the desired value), frozen in liquid nitrogen and stored at $-80{ }^{\circ} \mathrm{C}$ until RNA extraction. Chlorophyll a fluorescence was measured using a Pulse Amplitude Modulation 
Fluorometer (mini-PAM, Photosynthesis Yield Analyzer Walz, Germany), with a saturation pulse intensity extending up to $18000 \mu \mathrm{mol}$ photons $\mathrm{m}-2 \mathrm{~s}-1$ and actinic light corresponding to the Photosynthetically Active Radiation (PAR). Dark adaptation for chlorophyll a fluorescence was performed and the following measurements were undertaken: ground state fluorescence (Fo), maximal fluorescence $(\mathrm{Fm})$, variable fluorescence $(\mathrm{Fv}=\mathrm{Fm}-$ Fo) and maximum quantum yield of the PSII system $(\mathrm{Fv} / \mathrm{Fm}=[\mathrm{Fm}-\mathrm{Fo}] / \mathrm{Fm})$; together with the light adapted measurement of F'v/F'm.

\section{Field plant material and irrigation treatment}

The field trial plants, Touriga Nacional and Trincadeira, were from the grapevine selection collection, PORVID Association, Pegões, PT (38 38' 55 N; $\left.-8^{\circ} 39^{\prime} 14 \mathrm{O}\right)$.

The climate in the Pegões vineyard is Mediterranean with Atlantic influence with hot dry summer days and fresh nights, and mild winters (Additional file 1). The soil is derived from podzols, with a sandy surface layer $(0.6-1.0 \mathrm{~m})$ and clay at $1 \mathrm{~m}$ depth. Several genotypes of Touriga Nacional and Trincadeira were established in the vineyard. Both varieties were grafted on 1103 Paulsen rootstock in 2002. The plants are spaced $2.5 \mathrm{~m}$ between rows and $1 \mathrm{~m}$ within rows and trained on a vertical trellis with a pair of movable foliage wires for upward shoot positioning. In the field, only irrigation was used as treatments, thus two treatments were applied: full irrigated (FI) and non- irrigated (NI). Irrigation water in FI treatment was applied with drip emitters $\left(4.0 \mathrm{~L} \mathrm{~h}^{-1}\right.$ for $\left.\mathrm{FI}\right)$ two per vine, positioned $30 \mathrm{~cm}$ from the vine trunk. The water was supplied according to the crop's evapotranspiration (ETc.). Samples were taken simultaneously in both varieties when the pre-dawn leaf water potential was circa $-0.7 \mathrm{MPa}$ in the NI plants and higher than $-0.2 \mathrm{MPa}$ in the FI plants (Fig. 1). Samples consisted of the first and second totally expanded leaves, per plant and per treatment, which were frozen in liquid nitrogen until RNA extraction.

\section{RNA extraction}

Samples were ground with a mortar and pestle in the presence of liquid nitrogen. Total RNA was extracted using the Spectrum ${ }^{\text {Tw }}$ Plant Total RNA kit (Sigma-Aldrich, St. Louis, MO, USA). RNA quality and quantity were determined using a Nanodrop 2000 spectrophotometer (Thermo Scientific, Wilmington, DE, USA).

\section{Hybridization to Affymetrix GeneChips}

Thirty-six samples (three replicates per treatment including control plants) were analysed at the Genomics Unit of the Spanish National Centre for Biotechnology (CNB-CSIC, Madrid). RNA integrity analyses were done with an Agilent's Bioanalyzer 2100 using the NanoChip protocol [8]. The custom GrapeGen Affymetrix GeneChip (A-AFFY-162 and GPL11004 ArrayExpress and GEO accession numbers, respectively) [24], was processed as previously described [74]. Briefly, biotinylated RNA was prepared from $2 \mu \mathrm{g}$ of total RNA according to the standard Affymetrix protocol. After the first and second strand synthesis of cDNA in vitro transcription was performed using T7 RNA polymerase and biotinylated nucleotides, to produce biotin-labeled cRNA. Labelled cRNA was fragmented to the 50-200-bp size range, and each sample was added to a hybridization solution containing $100 \mathrm{mM}$ 2-(N-morpholino) ethanesulfonic acid, $1 \mathrm{M} \mathrm{Na}+$, and $20 \mathrm{mM}$ of EDTA in the presence of $0.01 \%$ of Tween-20 to a final cRNA concentration of $0.05 \mu \mathrm{g} / \mathrm{ml}$. Hybridization was performed for $16 \mathrm{~h}$ at $45^{\circ} \mathrm{C}$ [8]. Each GeneChip was washed and stained with streptavidin-phycoerythrin in a Fluidics Station 450 (Affymetrix) following the EukGE-WS2v5 script. After washing, the chips were scanned at $1.56 \mu \mathrm{m}$ resolution in a GeneChip Scanner 3000 7G System (Affymetrix). The software used was GeneChip Operating Software.

\section{Data analysis}

Eight data arrays from a total of 36 samples analysed (eight sample types in three biological replicates) were normalized to a baseline array with median CEL intensity by applying an Invariant Set Normalization Method [75]. Normalized CEL intensities of the arrays were used to obtain model-based gene expression indices based on a PM (Perfect Match)-only model [76]. Replicate data (triplicates) were weighted gene-wise by using inverse squared standard error as weights and analysed using the DNA-Chip Analyzer software. It allows assessment for expression indexes and calculation confidence intervals for fold changes. A lower confidence bound (LCB) cutoff between 1.2 and 1.3 was used to assess differentially expressed genes with a median False Discovery Rate (FDR) $<5 \%$ [76].

All transcripts were annotated following 12x_v2.1 draft annotation of the grapevine genome [21] allowing $70 \%$ of the genes to be identified within the 12x_v2.1 assembly reference genome. A gene was declared to be differentially expressed in a given condition only when it had a presence call in all three replicates. The subsequent validation of this approach was performed by RT-qPCR.

Microarray data analysed in this study have been submitted to the Gene Expression Omnibus (GEO) database (www.ncbi.nlm.nih.gov/geo/) under the number GSE57669.

\section{Principal component analysis (PCA)}

PCA projects high-dimensional data into lower dimensions by summarizing the variation of a high number of variables to a reduced number of principal components, and calculates the proportion of variation explained by 
each principal component [77]. Individual replicates of samples were projected into a three-dimensional space (http://www.partek.com/pgs) according to their expression data. The first three principal components were plotted.

\section{CDNA synthesis for RT-qPCR}

Nucleic acid concentration of each sample was quantified by spectrophotometry using the software Gen5 1.09 (Synergy HT, Bio-Tek Instruments, Winooski, USA). Total RNA quality was assessed using the $\mathrm{A}_{260} / \mathrm{A}_{280}$ and $\mathrm{A}_{260} / \mathrm{A}_{230}$. Only RNA samples with $\mathrm{A}_{260} / \mathrm{A}_{280}$ between 1.8 and 2.1 and $\mathrm{A}_{260} / \mathrm{A}_{230}$ between 2.0 and 2.2 were used. Total RNA integrity was checked through $1 \%$ agarose gel electrophoresis under denaturing conditions (data not shown). RNA samples were treated with RQ1 RNase-Free DNase (Promega, Madison, WI, USA). cDNA was synthesized from $2 \mu \mathrm{g}$ of total RNA using oligo $(\mathrm{dT})_{20}$ in a $20 \mu \mathrm{L}$-reaction volume using RevertAid Reverse Transcriptase (Fermentas Life Science, Helsingborg, Sweden) according to the manufacturer's recommendations. cDNA was stored at $-20{ }^{\circ} \mathrm{C}$ until further use.

\section{Gene selection for microarray validation and primer design}

Genes for the microarray validation were selected from the five most highly up-regulated genes and five most highly down-regulated genes for each variety/ treatment $\left(\log _{2}\right.$ [treatment/control] fold change higher than 2 or lower than -2). Deviations from this principle occurred when there was no NCBI accession number for the selected gene plus its functional category and annotation was unknown/no hit or repeated in the other five selected genes. In these cases, subsequent genes were selected providing their expression (in $\log _{2}$ ) was higher/lower than $2 /-2$. In Touriga Nacional (TN) under water (W) and light (L) stress the amount of transcripts was small and there were few or none with expression above or lower than 2/-2 therefore the most up or down-regulated genes were chosen. This resulted in a total selection of 65 genes across varieties/treatments (32 upregulated and 33 down-regulated). Primers for these genes were designed using the software Primer Premier 5.0 (Premier Biosoft International) using a primer length of $20 \pm 2 \mathrm{bp}$, melting temperature of $60{ }^{\circ} \mathrm{C} \pm$ $2{ }^{\circ} \mathrm{C}$, a guanine-cytosine content of circa $50 \%$ and an expected amplicon size of 180-280 bp (Additional file 11). We also checked, in silico, primer specificity compared to the grapevine $12 \mathrm{x} \_\mathrm{v} 2.1$ assembly reference genome (http://genomes.cribi.unipd.it/grape/).

\section{Real-Time qPCR}

The primer selection for RT-qPCR is of the utmost importance [78]. So we adopted primers and microarray probes to target the same exon to avoid possible bias introduced by the secondary structure of the cDNA [79] or by differential splicing. Special attention was also paid to the selection of the internal references and normalization methods, since they can influence the results significantly [80]. The real-time qPCR was performed in 96 well white reaction plates (Bio-Rad, Hercules, CA), using an IQ5 Real Time PCR (Bio-Rad, Hercules, CA) with three biological replicates and two technical replicates. The $20 \mu \mathrm{L}$ reaction mixture was composed of $1 \mu \mathrm{L}$ cDNA diluted 50-fold, $0.5 \mu \mathrm{M}$ of each gene-specific primer and $10 \mu \mathrm{L}$ master mix (SsoFast_EvaGreen Supermix, Bio-Rad, Hercules, CA). Amplification of PCR products was monitored via intercalation of EvaGreen (included in the master mix). The following program was applied: initial polymerase activation, $95{ }^{\circ} \mathrm{C}$, $3 \mathrm{~min}$; then 40 cycles at $94{ }^{\circ} \mathrm{C} 10 \mathrm{~s}$ (denaturation), $60{ }^{\circ} \mathrm{C}$ $20 \mathrm{~s}$ (annealing), $72{ }^{\circ} \mathrm{C} 15 \mathrm{~s}$ (extension), followed by a melting curve analysis to confirm the correct amplification of target gene fragments and the lack of primer dimmers. The PCR products were run on $2 \%$ agarose gels to make sure that there was only one amplicon of the expected size. PCRs with each primer pair were also performed on samples lacking cDNA template, in triplicate (no template controls). To assess amplification efficiency of the candidate genes, identical volumes of cDNA samples were diluted and used to generate five-point standard curves based on a five-fold dilution series $(1 ; 1: 5 ; 1: 25 ; 1: 125$; $1: 625)$, in triplicate. Amplification efficiency (E) is calculated as $E=10^{(-1 / a)}-1$, "a" being the slope of the linear regression curve $(y=a \log (x)+b)$ fitted over the $\log$ transformed data of the input cDNA dilution (y) plotted against the respective quantification cycle $(\mathrm{Cq})$ values $(\mathrm{x})$. E-values of the target genes were considered comparable when they did not exceed $100 \pm 10 \%$, corresponding to a standard curve slope of $3.3 \pm 0.33$. All cDNA samples were diluted 50 fold and were amplified in duplicate in two independent PCR runs.

To generate a baseline-subtracted plot of the logarithmic increase in fluorescence signal $(\Delta R n)$ versus cycle number, baseline data were collected between cycles 5 and 17. All amplification plots were analysed with an $R_{n}$ threshold of 0.2 at the beginning of the region of exponential amplification, to obtain $\mathrm{Cq}$ (quantification cycle) and the data obtained were exported into a MS Excel workbook (Microsoft Inc., USA) for analysis. Reference genes used were ACT, TIF and TIF-GTP [80].

\section{Statistical analysis of Real-time qPCR}

For the relation between the expressions of the selected genes and the reference genes the relative quantity 
values were transformed into $\log _{2}$ (thus rendering them parametric) and tested through ANOVA in the program SAS 9 (for Windows, SAS Institute Inc., Cary, NC, USA). When the $p$ value of the ANOVA was lower than 0.05 a Tukey test was performed and statistically significant differences were accepted for a $p$ value lower than 0.05 .

\section{Additional files}

Additional file 1: Maximal, medium and minimal temperatures and precipitation at Pegões Experimental Station (38 38 55 N; $-8^{\circ} 39^{\prime} 14$ W). (PDF $223 \mathrm{~kb}$ )

Additional file 2: Hierarchical cluster analysis (HCA) of microarray results for both varieties, Trincadeira and Touriga Nacional. (PDF 63 kb)

Additional file 3: Gene expression responses shared between the two varieties under high light and heat. TN, Touriga Nacional; TR, Trincadeira; $H$, heat stress; L, high light stress. (XLSX $14 \mathrm{~kb}$ )

Additional file 4: Genes exclusive and shared between field and growth room controlled stress treatments. (PDF $157 \mathrm{~kb}$ )

Additional file 5: Distribution in functional categories of differentially expressed genes in growth room and field experiments. (PDF $302 \mathrm{~kb}$ )

Additional file 6: Percentage of genes expressed after Heat, Light and Water stress growth room treatments in Trincadeira and Touriga Nacional plants in three selected functional categories. (PDF 290 kb)

Additional file 7: Functional categories of the selected up-and downregulated genes. (XLSX $19 \mathrm{~kb}$ )

Additional file 8: Validation of the microarray gene expression by RTqPCR. (PDF $31 \mathrm{~kb}$ )

Additional file 9: Correlation between the gene expression from the microarray and RT-qPCR analysis. (PDF $141 \mathrm{~kb}$ )

Additional file 10: Analyses of responsive transcripts in the Unknown Functional Category. (PDF $453 \mathrm{~kb}$ )

Additional file 11: Primers used for amplification of up- and downregulated genes by RT-qPCR. (XLSX $13 \mathrm{~kb}$ )

\section{Abbreviations}

ABA: Abscisic acid; ACT: Actin gene; C: Control sample; ${ }^{\circ} \mathrm{C}$ : Degrees Celsius; ELIP: Early Light-Inducible Protein; FDR: False Discovery Rate; FI: Full irrigation; FTN: Field Touriga Nacional; FTR: Field Trincadeira; h: Hours; H: Heat; HCA: Hierarchical clustering analysis; IS: Individual stress; L: High light; LH: High light;heat; LTR: Long terminal repeats; m: Meter; MPa: Mega Pascal; NI: No irrigation; PCA: Principal component analysis; PC1: Principal component 1; PC2: Principal component 2; PSIl: Photosystem II; RTQPCR: Quantitative reverse transcriptase-polymerase chain reaction; TEs: Transposable elements; TF: Transcription factor; TIF: Translation initiation factor elF-3 subunit 4; TIF-GTP: Translation initiation factor elF-2B alpha subunit: TN: Touriga Nacional: TN H: Touriga Nacional Heat stress; TN L: Touriga Nacional High Light stress; TN W: Touriga Nacional Water stress; TR: Trincadeira; TR H: Trincadeira Heat stress; TR L: Trincadeira High Light stress; TR W: Trincadeira Water stress; W: Drought stress; WH: Water;heat stress; WL: Water;high light stress; WLH: Water;high light;heat stress

\section{Acknowledgements}

The authors would like to thank Jose Miguel Zapater from Genomics Unit of the Spanish National Centre for Biotechnology (CNB-CSIC, Madrid). The field work was performed at PORVID Association (Pegões, PT) and the authors thank the president of its executive board, Prof. Antero Martins.

\section{Funding}

The research was funded by Fundação para a Ciência e Tecnologia (FCT): project PTDC/AGR-GPL/099624/2008; LEAF (UID/AGR/04129/2013); the postdoc grants SFRH/BPD/64905/2009 to MR and SFRH/BPD/85767/2012 to LC and PhD grants SFRH/BD/85824/2012 to JLC and SFRH/BD/110274/2015 to MJNR.

\section{Availability of data and materials}

The microarray sets supporting the results of this article have been submitted to the Gene Expression Omnibus (GEO) database (www.ncbi.nlm.nih.gov/geo/) under the number GSE57669.

\section{Authors' contributions}

MR and SA conceived the study. MR and JDB performed the array analysis. $J L C$ and LC carried out the experimental work. MR and MJNR performed the bioinformatics analysis. MR, JLC, LC drafted the manuscript. PCB and SA contributed to the revised and final version of the manuscript. All authors read and approved the final version of the manuscript.

\section{Competing interests}

The authors declare that they have no competing interests.

\section{Consent for publication}

Not applicable.

\section{Ethics approval and consent to participate}

Not applicable.

\section{Author details}

${ }^{1}$ Instituto Superior de Agronomia, LEAF, Linking Landscape, Environment, Agriculture and Food, Universidade de Lisboa, 1349-017 Lisboa, Portugal. ${ }^{2}$ Instituto Gulbenkian de Ciência, 2780-156 Oeiras, Portugal. ${ }^{3}$ Instituto de Ciencias de la Vid y del Vino, CSIC-Universidad de La Rioja-Gobierno de la Rioja, 26007 Logroño, Spain.

Received: 31 May 2016 Accepted: 28 September 2016

Published online: 12 October 2016

\section{References}

1. Jones GV, White MA, Owen RC, Storchmann C. Climate change and global wine quality. Clim Change. 2005;73:319-43.

2. Chaves MM, Flexas J, Pinheiro C. Photosynthesis under drought and salt stress: regulation mechanisms from whole plant to cell. Ann Bot. 2009:103:551-60.

3. Chaves MM, Santos TP, Souza CR, Ortuño MF, Rodrigues ML, Lopes CM, et al. Deficit irrigation in grapevine improves water-use efficiency while controlling vigour and production quality. Ann Appl Biol. 2007;150:237-52.

4. White MA, Diffenbaugh NS, Jones GV, Pal JS, Giorgi F. Extreme heat reduces and shifts United States premium wine production in the 21st century. Proc Natl Acad Sci U S A. 2006;103(30):11217-22.

5. Hannah L, Roehrdanz PR, lkegami M, Shepard AV, Shaw MR, Tabor G, et al. Climate change, wine, and conservation. Proc Natl Acad Sci U S A. 2013:110(17):6907-12.

6. Chaves M, Zarrouk O, Francisco R, Costa J, Santos T, Regalado A, et al. Grapevine under deficit irrigation: hints from physiological and molecular data. Ann Bot. 2010;105(5):661-76.

7. Cramer GR. Abiotic stress and plant responses from the whole vine to the genes. Aust J Grape Wine Res. 2010;16:86-93.

8. Rocheta M, Becker JD, Coito JL, Carvalho L, Amancio S. Heat and water stress induce unique transcriptional signatures of heat-shock proteins and transcription factors in grapevine. Funct Integr Genomics. 2014;14(1):135-48.

9. Rizhsky L, Liang H, Shuman J, Shulaev V, Davletova S, Mittler R. When defense pathways collide. The response of Arabidopsis to a combination of drought and heat stress. Plant Physiol. 2004;134(4):1683-96.

10. Mittler R. Abiotic stress, the field environment and stress combination. Trends Plant Sci. 2006:11:15-9.

11. Agudelo-Romero P, Erban A, Sousa L, Pais MS, Kopka J, Fortes AM. Search for transcriptional and metabolic markers of grape pre-ripening and ripening and insights into specific aroma development in three Portuguese cultivars. PLoS One. 2013;8, e60422.

12. Costa JM, Ortuño MF, Lopes CM, Chaves MM. Grapevine varieties exhibiting differences in stomatal response to water deficit. Funct Plant Biol. 2012;39(3):179-89.

13. Carvalho LC, Coito JL, Colaço S, Sangiogo M, Amancio S. Heat stress in grapevine: the pros and cons of acclimation. Plant Cell Environ. 2015;38(4):777-89.

14. Rizhsky L, Hongjian L, Mittler R. The combined effect of drought stress and heat shock on gene expression in tobacco. Plant Physiol. 2002;130:1143-51. 
15. Xiong L, Wang RG, Mao G, Koczan JM. Identification of drought tolerance determinants by genetic analysis of root response to drought stress and abscisic acid. Plant Physiol. 2006;142(3):1065-74.

16. Cramer GR, Ergul A, Grimplet J, Tillett RL, Tattersall EA, Bohlman MC, et al. Water and salinity stress in grapevines: early and late changes in transcript and metabolite profiles. Funct Integr Genomics. 2007;7(2):111-34

17. Dal Santo S, Tornielli GB, Zenoni S, Fasoli M, Farina L, Anesi A, et al. The plasticity of the grapevine berry transcriptome. Genome Biol. 2013;14(6):r54.

18. Carvalho LC, Vilela BJ, Mullineaux PM, Amancio S. Comparative transcriptomic profiling of Vitis vinifera under high light using a custommade array and the Affymetrix GeneChip. Mol Plant. 2011;4(6):1038-51.

19. Liu GT, Wang JF, Cramer G, Dai ZW, Duan W, Xu HG, et al. Transcriptomic analysis of grape (Vitis vinifera $\mathrm{L}$.) leaves during and after recovery from heat stress. BMC Plant Biol. 2012;12:174.

20. Xin H, Zhu W, Wang L, Xiang Y, Fang L, Li J, et al. Genome wide transcriptional profile analysis of Vitis amurensis and Vitis vinifera in response to cold stress. PLoS One. 2013;8(3), e58740.

21. Grimplet J, Van Hemert J, Carbonell-Bejerano P, Diaz-Riquelme J, Dickerson J, Fennell A, et al. Comparative analysis of grapevine whole-genome gene predictions, functional annotation, categorization and integration of the predicted gene sequences. BMC Res Notes. 2012;5:213.

22. Carvalho LC, Coito JL, Goncalves EF, Chaves MM, Amancio S. Differential physiological response of the grapevine varieties Touriga Nacional and Trincadeira to combined heat, drought and light stresses. Plant Biol (Stuttg). 2015.

23. Wang M, Vannozzi A, Wang G, Zhong Y, Corso M, Cavallini E, et al. A comprehensive survey of the grapevine VQ gene family and its transcriptional correlation with WRKY proteins. Front Plant Sci. 2015;6:417.

24. Lijavetzky D, Carbonell-Bejerano P, Grimplet J, Bravo G, Flores P, Fenoll J, et al. Berry flesh and skin ripening features in Vitis vinifera as assessed by transcriptional profiling. PLoS One. 2012;7(6), e39547.

25. Diaz-Riquelme J, Grimplet J, Martinez-Zapater JM, Carmona MJ. Transcriptome variation along bud development in grapevine (Vitis vinifera L.). BMC Plant Biol. 2012;12:181.

26. Dal Santo S, Vannozzi A, Tornielli GB, Fasoli M, Venturini L, Pezzotti M, et al. Genome-wide analysis of the expansin gene superfamily reveals grapevinespecific structural and functional characteristics. PLoS One. 2013;8(4), e62206

27. Chen W, Provart NJ, Glazebrook J, Katagiri F, Chang H-S, Thomas E, et al. Expression profile matrix of Arabidopsis transcription factor genes suggests their putative functions in response to environmental stresses. Plant Cell. 2002;14:559-74

28. Gonzalez-Perez S, Gutierrez J, Garcia-Garcia F, Osuna D, Dopazo J, Lorenzo O, et al. Early transcriptional defense responses in Arabidopsis cell suspension culture under high-light conditions. Plant Physiol. 2011;156(3):1439-56.

29. McLennan AG. The Nudix hydrolase superfamily. Cell Mol Life Sci. 2006:63(2):123-43.

30. Kraszewska E. The plant Nudix hydrolase family. Acta Biochim Pol. 2008;55(4):663-71.

31. Bartsch M, Gobbato E, Bednarek P, Debey S, Schultze JL, Bautor J, et al. Salicylic acid-independent Enhanced Disease Susceptibility1 signaling in Arabidopsis immunity and cell death is regulated by the monooxygenase FMO1 and the Nudix hydrolase NUDT7. Plant Cell. 2006:18(4):1038-51.

32. Magnard JL, Roccia A, Caissard JC, Vergne P, Sun P, Hecquet R, et al. Plant Volatiles. Biosynthesis of monoterpene scent compounds in roses. Science. 2015;349(6243):81-3.

33. Baena-Gonzalez E. Energy signaling in the regulation of gene expression during stress. Mol Plant. 2010;3(2):300-13.

34. Hopper DW, Ghan R, Schlauch KA, Cramer GR. Transcriptomic network analyses of leaf dehydration responses identify highly connected $A B A$ and ethylene signaling hubs in three grapevine species differing in drought tolerance. BMC Plant Biol. 2016;16(1):118.

35. Bobeica N, Poni S, Hilbert G, Renaud C, Gomes E, Delrot S, et al. Differential responses of sugar, organic acids and anthocyanins to source-sink modulation in Cabernet Sauvignon and Sangiovese grapevines. Front Plant Sci. 2015;6:382

36. Venturini L, Ferrarini A, Zenoni S, Tornielli GB, Fasoli M, Dal Santo S, et al. De novo transcriptome characterization of Vitis vinifera cv. Corvina unveils varietal diversity. BMC Genomics. 2013;14:41.

37. Renaut J, Hausman J-F, Bassett C, Artlip T, Cauchie H-M, Witters E, et al. Quantitative proteomic analysis of short photoperiod and low-temperature responses in bark tissues of peach (Prunus persica L. Batsch). Tree Genet Genomes. 2008;4(4):589-600.

38. Harb A, Krishnan A, Ambavaram MMR, Pereira A. Molecular and physiological analysis of drought stress in Arabidopsis reveals early responses leading to acclimation in plant growth. Plant Physiol. 2010;154(3):1254-71.

39. Zhao MR, Li F, Fang Y, Gao Q, Wang W. Expansin-regulated cell elongation is involved in the drought tolerance in wheat. Protoplasma. 2011;248(2):313-23.

40. Matus JT, Aquea F, Arce-Johnson P. Analysis of the grape MYB R2R3 subfamily reveals expanded wine quality-related clades and conserved gene structure organization across Vitis and Arabidopsis genomes. BMC Plant Biol. 2008:8:83.

41. Cavallini E, Matus JT, Finezzo L, Zenoni S, Loyola R, Guzzo F, et al. The phenylpropanoid pathway is controlled at different branches by a set of R2R3MYB C2 repressors in grapevine. Plant Physiol. 2015;167(4):1448-U1552.

42. Diedhiou CJ, Popova OV, Dietz KJ, Golldack D. The SNF1-type serinethreonine protein kinase SAPK4 regulates stress-responsive gene expression in rice. BMC Plant Biol. 2008;8:49.

43. Mizoguchi M, Umezawa T, Nakashima K, Kidokoro S, Takasaki H, Fujita Y, et al. Two closely related subclass II SnRK2 protein kinases cooperatively regulate drought-inducible gene expression. Plant Cell Physiol. 2010;51(5):842-7.

44. Mao X, Zhang H, Tian S, Chang X, Jing R. TaSnRK2.4, an SNF1-type serine/ threonine protein kinase of wheat (Triticum aestivum L.), confers enhanced multistress tolerance in Arabidopsis. J Exp Bot. 2010;61(3):683-96.

45. Gershater MC, Edwards R. Regulating biological activity in plants with carboxylesterases. Plant Sci. 2007;173(6):579-88.

46. Taji T, Ohsumi C, luchi S, Seki M, Kasuga M, Kobayashi M, et al. Important roles of drought- and cold-inducible genes for galactinol synthase in stress tolerance in Arabidopsis thaliana. Plant J. 2002;29(4):417-26.

47. Downie B, Gurusinghe S, Dahal P, Thacker RR, Snyder JC, Nonogaki H, et al. Expression of a Galactinol synthase gene in tomato seeds is up-regulated before maturation desiccation and again after imbibition whenever radicle protrusion is prevented. Plant Physiol. 2003;131(3):1347-59.

48. Pillet J, Egert A, Pieri P, Lecourieux F, Kappel C, Charon J, et al. VvGOLS1 and $V_{V} H s f A 2$ are involved in the heat stress responses in grapevine berries. Plant Cell Physiol. 2012;53(10):1776-92.

49. Carbonell-Bejerano P, Santa Maria E, Torres-Perez R, Royo C, Lijavetzky D, Bravo $G$, et al. Thermotolerance responses in ripening berries of Vitis vinifera L. cv Muscat Hamburg. Plant Cell Physiol. 2013;54(7):1200-16.

50. Li C, Wang M, Wu XM, Chen DH, Lv HJ, Shen JL, et al. THI1, a thiamine thiazole synthase, interacts with Ca2 +-dependent protein kinase CPK33 and modulates the S-type anion channels and stomatal closure in Arabidopsis. Plant Physiol. 2015.

51. Machado CR, de Oliveira RL, Boiteux S, Praekelt UM, Meacock PA, Menck CF. Thi1, a thiamine biosynthetic gene in Arabidopsis thaliana, complements bacterial defects in DNA repair. Plant Mol Biol. 1996:31(3):585-93.

52. Machado CR, Praekelt UM, de Oliveira RC, Barbosa AC, Byrne KL, Meacock PA, et al. Dual role for the yeast THI4 gene in thiamine biosynthesis and DNA damage tolerance. J Mol Biol. 1997;273(1):114-21.

53. Grebe M, Xu J, Mobius W, Ueda T, Nakano A, Geuze HJ, et al. Arabidopsis sterol endocytosis involves actin-mediated trafficking via ARA6-positive early endosomes. Curr Biol. 2003:13(16):1378-87.

54. Licausi F, Giorgi FM, Zenoni S, Osti F, Pezzotti M, Perata P. Genomic and transcriptomic analysis of the AP2/ERF superfamily in Vitis vinifera. BMC Genomics. 2010;11:719.

55. Cramer GR, Ghan R, Schlauch KA, Tillett RL, Heymann H, Ferrarini $A$, et al. Transcriptomic analysis of the late stages of grapevine (Vitis vinifera CV. Cabernet Sauvignon) berry ripening reveals significant induction of ethylene signaling and flavor pathways in the skin. BMC Plant Biol. 2014;14:370.

56. Reddy AS, Ben-Hur A, Day IS. Experimental and computational approaches for the study of calmodulin interactions. Phytochemistry. 2011;72(10):1007-19.

57. Ingram J, Bartels D. The molecular basis of dehydration tolerance in plants. Annu Rev Plant Physiol Plant Mol Biol. 1996;47:377-403.

58. Bies-Etheve N, Gaubier-Comella P, Debures A, Lasserre E, Jobet E, Raynal M, et al. Inventory, evolution and expression profiling diversity of the LEA (late embryogenesis abundant) protein gene family in Arabidopsis thaliana. Plant Mol Biol. 2008;67(1-2):107-24.

59. Pandey SP, Somssich IE. The role of WRKY transcription factors in plant immunity. Plant Physiol. 2009;150(4):1648-55. 
60. Cao H, Glazebrook J, Clarke JD, Volko S, Dong X. The Arabidopsis NPR1 gene that controls systemic acquired resistance encodes a novel protein containing ankyrin repeats. Cell. 1997;88(1):57-63.

61. Prasch CM, Sonnewald U. Simultaneous application of heat, drought, and virus to Arabidopsis plants reveals significant shifts in signaling networks. Plant Physiol. 2013;162(4):1849-66.

62. Zhu Z, Shi J, Xu W, Li H, He M, Xu Y, et al. Three ERF transcription factors from Chinese wild grapevine Vitis pseudoreticulata participate in different biotic and abiotic stress-responsive pathways. J Plant Physiol. 2013;170(10):923-33.

63. Rasmussen $S$, Barah $P$, Suarez-Rodriguez MC, Bressendorff $S$, Friis $P$, Costantino P, et al. Transcriptome responses to combinations of stresses in Arabidopsis. Plant Physiol. 2013;161(4):1783-94.

64. McClintock B. The significance of responses of the genome to challenge. Science. 1984;226(4676):792-801.

65. Wessler SR. Turned on by stress. Plant retrotransposons. Curr Biol. 1996;6(8): 959-61.

66. Velasco R, Zharkikh A, Troggio M, Cartwright DA, Cestaro A, Pruss D, et al. A high quality draft consensus sequence of the genome of a heterozygous grapevine variety. PLoS ONE. 2007;2, e1326.

67. Vannini C, Iriti M, Bracale M, Locatelli F, Faoro F, Croce P, et al. The ectopic expression of the rice Osmyb4 gene in Arabidopsis increases tolerance to abiotic, environmental and biotic stresses. Physiol Mol Plant Pathol. 2006;69:26-42.

68. Ismail AM, Hall AE, Close TJ. Purification and partial characterization of a dehydrin involved in chilling tolerance during seedling emergence of cowpea. Plant Physiol. 1999;120(1):237-44.

69. Casacuberta $\mathrm{E}$, Gonzalez J. The impact of transposable elements in environmental adaptation. Mol Ecol. 2013;22(6):1503-17.

70. Sakai $\mathrm{H}$, Tanaka T, Itoh T. Birth and death of genes promoted by transposable elements in Oryza sativa. Gene. 2007;392(1-2):59-63.

71. Zeh DW, Zeh JA, Ishida Y. Transposable elements and an epigenetic basis for punctuated equilibria. BioEssays. 2009;31(7):715-26.

72. Rhue RD, Grogan CO, Stockmeyer EW, Everett HL. Genetic control of aluminum tolerance in corn. Crop Sci. 1978:18:1063-7.

73. Chaves MM, Pereira JS, Maroco J, Rodrigues ML, Ricardo CPP, Osório ML, et al. How plants cope with water stress in the field? Photosynthesis and growth. Ann Bot. 2002;89:907-16.

74. Pontin M, Piccoli P, Francisco R, Bottini R, Martinez-Zapater J, Lijavetzky D. Transcriptome changes in grapevine (Vitis vinifera L.) CV. Malbec leaves induced by ultraviolet-B radiation. BMC Plant Biol. 2010;10:224.

75. Li C, Wong WH. Model-based analysis of oligonucleotide arrays: model validation, design issues and standard error application. Genome Biol. 2001;2(8):1-11.

76. Li C, Wong WH. Model-based analysis of oligonucleotide arrays: expression index computation and outlier detection. Proc Natl Acad Sci U S A. 2001;98(1):31-6.

77. Raychaudhuri S, Stuart JM, Altman RB. Principal components analysis to summarize microarray experiments: application to sporulation time series. Pac Symp Biocomput. 2000;5:455-466.

78. Thallinger GG, Obermayr E, Charoentong P, Tong D, Trajanoski Z, Zeillinger R. A sequence based validation of gene expression microarray data. Am J Bioinform. 2012;1(1):1-9.

79. Zhang YJ, Pan HY, Gao SJ. Reverse transcription slippage over the mRNA secondary structure of the LIP1 gene. BioTechniques. 2001;31(6):1286-1294

80. Coito JL, Rocheta M, Carvalho L, Amâncio S. Microarray-based uncovering reference genes for quantitative real time PCR in grapevine under abiotic stress. BMC Res Notes. 2012;5:220

\section{Submit your next manuscript to BioMed Central and we will help you at every step:}

- We accept pre-submission inquiries

- Our selector tool helps you to find the most relevant journal

- We provide round the clock customer support

- Convenient online submission

- Thorough peer review

- Inclusion in PubMed and all major indexing services

- Maximum visibility for your research

Submit your manuscript at www.biomedcentral.com/submit

) Biomed Central 